\title{
Cyclin-Dependent Kinase 5 Phosphorylation of Human Septin SEPT5 (hCDCrel-1) Modulates Exocytosis
}

\author{
Niranjana D. Amin, ${ }^{1 \star}$ Ya-Li Zheng, ${ }^{1 \star}$ Sashi Kesavapany, ${ }^{2 *}$ Jyotshnabala Kanungo, ${ }^{1}$ Tad Guszczynski, ${ }^{3}$ Ram K. Sihag, ${ }^{1}$ \\ Parvathi Rudrabhatla, ${ }^{1}$ Wayne Albers, ${ }^{1}$ Philip Grant, ${ }^{1}$ and Harish C. Pant ${ }^{1}$ \\ ${ }^{1}$ Laboratory of Neurochemistry, National Institute of Neurological Disorders and Stroke, National Institutes of Health, Bethesda, Maryland 20892, ${ }^{2}$ Yong \\ Loo Lin School of Medicine, National University of Singapore, Singapore 117597, Singapore, and ${ }^{3}$ Protein Chemistry Core, Laboratory of Cell and \\ Developmental Signaling, National Cancer Institute, Frederick, Maryland 21702
}

Cyclin-dependent kinase 5(Cdk5) is predominantly expressed in the nervous system, where it is involved in neuronal migration, synaptic transmission, and survival. The role of $\mathrm{Cdk} 5$ in synaptic transmission is mediated by regulating the cellular functions of presynaptic proteins such as synapsin, Munc18, and dynamin 1. Its multifunctional role at the synapse is complex and probably involves other novel substrates. To explore this possibility, we used a yeast two-hybrid screen of a human cDNA library with p35 as bait and isolated human septin 5 (SEPT5), known also as hCDCrel-1, as an interacting clone. Here we report that p35 associates with SEPT5 in GST (glutathione $S$-transferase)-pull-down and coimmunoprecipitation assays. We confirmed that $\mathrm{Cdk} 5 / \mathrm{p} 35$ phosphorylates SEPT5 in vitro and in vivo and identified S327 of SEPT5 as a major phosphorylation site. A serine (S)-to-alanine (A) 327 mutant of SEPT5 bound syntaxin more efficiently than SEPT5 wild type. Additionally, coimmunoprecipitation from synaptic vesicle fractions and Cdk5 wild-type and knock-out lysates showed that phosphorylation of septin 5 by $\mathrm{Cdk} 5 / \mathrm{p} 35$ decreases its binding to syntaxin-1. Moreover, mutant nonphosphorylated SEPT5 potentiated regulated exocytosis more than the wild type when each was expressed in PC12 cells. These data suggest that Cdk5 phosphorylation of human septin SEPT5 at S327 plays a role in modulating exocytotic secretion.

Key words: Cdk5; SEPT5; phosphorylation; syntaxin; secretion; hGH

\section{Introduction}

Activity of cyclin-dependent kinase 5 (Cdk5), a proline-directed serine/threonine protein kinase (Lew et al., 1992a,b), is restricted to the neural and muscular systems because of its association with specific activators p35 and p39 (Tsai et al., 1994; Dhavan and Tsai, 2001; Lai and Ip, 2003). The Cdk5/p35 complex is essential for neuronal migration during development of the laminar configuration of the cerebral cortex (Ohshima et al., 1996; Chae et al., 1997). Cdk5 and its activators are enriched in nerve terminals, are localized to vesicular fractions, and have been implicated in membrane trafficking in neurons during process outgrowth $(\mathrm{Pa}-$ glini et al., 2001). Cdk5 activity has essential roles in synaptic function, including phosphorylation of receptor subunits (Li et al., 2000). Because of its multifunctional behavior, its role at the presynaptic terminal is likely to be complex (Cheung et al., 2006). It is one of several kinases that phosphorylate synapsin, a synaptic vesicle protein (Matsubara et al., 1996). Together with p35, Cdk5

Received June 28, 2007; accepted Feb. 21, 2008.

This work was supported by the National Institutes of Health (NIH)-National Institute of Neurological Disorders and Stroke (NINDS) intramural funds. We thank Dr. Carolyn Smith of the NINDS Light Imaging Facility for her assistance with confocal microscopy studies. We also thank Christine Winters for providing rat brains. We thank Dr. P. McPhie, National Institute of Diabetes and Digestive and Kidney Diseases, NIH, for his help in CD spectroscopy.

${ }^{*}$ N.D.A., Y.-L.Z., and S.K. contributed equally to this work.

Correspondence should be addressed to Dr. Harish C. Pant, Laboratory of Neurochemistry, National Institute of Neurological Disorders and Stroke, National Institutes of Health, Building 49, Room 2A28, 49 Convent Drive, Bethesda, MD 20892-4130. E-mail: panth@ninds.nih.gov.

D01:10.1523/JNEUROSCI.0453-08.2008

Copyright $\odot 2008$ Society for Neuroscience $\quad 0270-6474 / 08 / 283631-13 \$ 15.00 / 0$ forms a complex with syntaxin and nsec-1 (Munc18), key proteins in synaptic fusion and release (Shuang et al., 1998), and phosphorylates dynamin 1 , functioning as a modulator of endocytosis during repeated cycles of stimulation (Smillie and Cousin, 2005).

Because phosphorylation-dephosphorylation events act as "switches" in synaptic regulation, a tightly regulated C $\mathrm{dk} 5$ phosphorylation of various presynaptic proteins needs to be properly orchestrated to ensure repeated bouts of synaptic transmission. To fully understand the mechanisms involved, all protein players must be identified and characterized. With p35 or p39 as bait in yeast two-hybrid screens, several Cdk5 target proteins have been identified, such as a Cdk5/p35-regulated membrane-associated kinase (Kesavapany et al., 2003), RasGRF2 (Ras guanine nucleotide-releasing factor 2) (Kesavapany et al., 2004), and two proteins localized at postsynaptic densities, $\alpha$-actinin 1 and CAM kinase II (Dhavan et al., 2002). Recently, another Cdk5 target at the synapse has been identified in rodent brain synaptosomes, namely Sept5 (Taniguchi et al., 2007). This adult-type septin 5 isoform (Sept5_v1) was shown to be phosphorylated by Cdk5/ p35 at S17 in the N-terminal region, thereby inhibiting binding of septin 5 to syntaxin, a key player in the SNARE complex.

Encouraged by these studies, we have applied a similar yeast two-hybrid strategy, using p25, a truncated form of p35, as bait in an adult human brain cDNA library. Among several putative proteins we extracted was human septin 5 (SEPT5), previously called hCDCrel-1 (Macara et al., 2002), one of many septins spe- 
cific to the brain, which colocalizes with synaptic vesicles and is involved in exocytosis (Xue et al., 2004; Beites et al., 2005). Previous studies relating septin 5 to synaptic vesicle proteins and exocytosis have been performed with rat septin 5 (Beites et al., 1999). Therefore, to distinguish these species variants, we have designated human and rat septin 5 as SEPT5 and Sept5, respectively (Macara et al., 2002).

Here, we show that p35 binds to SEPT5, which, together with Cdk 5 and SNARE proteins, colocalize in putative synaptic sites in cultured rat cortical neurons. In vitro and in vivo Cdk $5 / \mathrm{p} 35$ phosphorylates SEPT5 at a major S327 site adjacent to the C-terminal coiled-coil domain and a minor S161 site in the GTP-binding domain. It should be noted that an S17 is not present in the human SEPT5 isoform, which is similar to the mouse fetal type septin 5 splice variant Sept5_v2 (Taniguchi et al., 2007). In purified synaptic vesicle preparations, Cdk5/p35 associated with septin 5 and phospho-SEPT5 [Ser $\left.(\mathrm{P})^{327}\right]$ accompanied by a reduction in syntaxin-1 binding. Most interestingly, although SEPT5 with an alanine mutation at S327 binds syntaxin more efficiently than the wild type (WT), after transfection into PC12 cells, the mutant potentiates regulated secretion of human growth hormone $(\mathrm{hGH})$ protein more than the wild type. These findings suggest that SEPT5's role in exocytotic secretion is modulated by Cdk5 phosphorylation at $\mathrm{S} 327$.

\section{Materials and Methods}

Constructs and cells. A SEPT5 fragment (Frag.) 200-369 aa isolated from the yeast two-hybrid screen was cloned into pCMV-Myc vector (BD Biosciences, San Jose, CA) and pGEX6P-2 vector (GE Healthcare, Piscataway, NJ). SEPT5 full length (F.L.) in pDEST 40 was a generous gift from Dr. Mark Cookson [National Institute on Aging, National Institutes of Health (NIH), Bethesda, MD] and was cloned as described above. p25, p35, and Cdk5 cDNAs in pcDNA3.1C vectors were gifts from Dr. Li-Huei Tsai (Massachusetts Institute of Technology, Cambridge, MA). The putative phosphorylation sites in SEPT5 were mutated using the QuickChange site-directed mutagenesis kit (Stratagene, La Jolla, CA) and were verified by DNA sequencing. The plasmid pXGH5 encoding human growth hormone gene was a gift from Prof. Masami Takahashi (Mitsubishi Kagaku Institute of Life Sciences, Tokyo, Japan). PC12 cells were purchased from American Type Culture Collection (Manassas, VA).

Antibodies and reagents. Antibodies like polyclonal goat (C-20) and monoclonal (SP18) septin 5, monoclonal syntaxin-1(HPC-1), polyclonal syntaxin-1, polyclonal SNAP-25, polyclonal $\alpha$-SNAP, Cdk5 (C8), and p35 (C19) were purchased from Santa Cruz Biotechnology (Santa Cruz, CA). Septin 5 polyclonal rabbit was purchased from Proteintech Group (Chicago, IL), and monoclonal Xpress epitope tag antibody was purchased from Invitrogen (Carlsbad, CA). Polyclonal and monoclonal Myc and polyclonal and monoclonal $\beta$-actin antibodies were purchased from Sigma (St. Louis, MO). Monoclonal hGH antibody was obtained from Lab Vision (Fremont, CA). Polyclonal Vamp-2 and monoclonal SNAP-25 antibodies were purchased from Abcam (Cambridge, MA). Monoclonal p35 antibody was obtained from Millipore (Billerica, MA). Monoclonal synapsin antibody was provided by Dr. Susan Cheng (National Institute of Neurological Disorders and Stroke, NIH). Secondary horseradish peroxidase-conjugated antibodies were obtained from GE Healthcare. Secondary fluorescence-conjugated Alexa-Fluor, Oregon Green, and Texas Red antibodies were purchased from Invitrogen. Roscovitine was purchased from Biomol International (Plymouth Meeting, PA). Active Cdk5/p35 was purchased from Millipore. Fugene 6 and hGH ELISA kit were purchased from Roche (Indianapolis, IN). Synaptic vesicle isolation kit was purchased from Sigma. $\left[{ }^{32} \mathrm{P}\right]$-orthophosphate and $\left[\gamma_{-}{ }^{32} \mathrm{P}\right]$ ATP were purchased from PerkinElmer Life and Analytical Sciences (Waltham, MA). Service for phosphopeptide synthesis and generation of phospho-specific anti-Ser $(\mathrm{P})^{327}$ antibody was provided by Cedarlane Laboratories (Burlington, NC). The phosphopeptide sequence was KLTQDSRMES(PO4)PIPILPL.
Yeast two-hybrid system. Yeast two-hybrid System 3 (Clontech, Mountain View, CA) was used to perform two-hybrid screen experiments according to the manufacturer's instructions. All experimental procedures are as described previously (Kesavapany et al., 2004).

Recombinant expression of GST-SEPT5 and GST-pull-down assays. Expression and purification of the glutathione $S$-transferase (GST) and GST-SEPT5 full-length and fragment fusion proteins were performed essentially as described previously (Amin et al., 2002). GST-pull-down assays were performed as described previously (Kesavapany et al., 2001). Briefly, GST or GST-SEPT5 F.L. or GST-SEPT5 Frag. were first immobilized on glutathione Sepharose beads in PBS and incubated at $4^{\circ} \mathrm{C}$ for $2 \mathrm{~h}$, the beads were washed with PBS three times and used as bait in transfected CHO cell lysates. Samples were separated by SDS-PAGE and subjected to Western blotting. For syntaxin-1-binding experiments, GST fusion SEPT5 wild-type and SEPT5 mutant (S161A, S327A, and S161A/ $\mathrm{S} 327 \mathrm{~A})$ proteins were phosphorylated in the kinase reaction buffer containing $0.5 \mathrm{~mm}$ cold ATP and an active $\mathrm{Cdk} 5 / \mathrm{p} 35$ (Millipore) at $30^{\circ} \mathrm{C}$ for $1 \mathrm{~h}$. The phosphorylated proteins were immobilized on glutathione Sepharose beads and were incubated with $250 \mu \mathrm{g}$ of cortical neuron lysates by incubating at $4^{\circ} \mathrm{C}$ for $2 \mathrm{~h}$. After the wash, the beads were subjected to SDS-PAGE and Western blotting.

Immunoprecipitation. Immunoprecipitations (IPs) from transfected CHO cells, HEK 293 cells, and cortical neurons were performed essentially as described previously (Kesavapany et al., 2004). For rat brain coimmunoprecipitation studies, $10 \%$ rat brain homogenates were prepared using ice-cold IP lysis buffer, and $250 \mu \mathrm{g}$ of protein was used.

Immunocytochemistry. Immunocytochemical (ICC) analyses of cortical neurons were performed essentially as described previously (Kesavapany et al., 2004). Fluorescent images were acquired using a Zeiss (Thornwood, NY) LSM510 confocal microscope, and images were managed in Adobe (San Jose, CA) Photoshop.

Phosphorylation, electrophoresis, and autoradiography. Active Cdk5 from rat brain lysates or from Millipore was used for phosphorylation of GST-SEPT5. Active Cdk5 was immunoprecipitated from $250 \mu \mathrm{g}$ of rat brain lysates by using a well characterized Cdk5 antibody (C8) as described previously (Veeranna et al., 1998). The bacterially expressed GST-SEPT5 was phosphorylated essentially as described previously (Amin et al., 2002). Briefly, 1-2 $\mu \mathrm{g}$ of GST-SEPT5 protein was incubated with $2 \mathrm{U}$ of active $\mathrm{Cdk} 5$ (or Cdk5 immunoprecipitated from $500 \mu \mathrm{g}$ of rat brain lysates) for $30 \mathrm{~min}$ at $30^{\circ} \mathrm{C}$ in a kinase reaction buffer as described previously (Veeranna et al., 1998). The Laemmli sample buffer $(5 \times)$ was added, and the proteins were subjected to SDS-PAGE. The gels were stained with Coomassie blue, and the radioactive bands were visualized on a Fuji phosphor imager (Fujifilm Medical Systems, Stamford, CT).

Phosphoamino acid analyses. For phosphoamino acid analyses, a tryptic digest of ${ }^{32} \mathrm{P}$-labeled SEPT5 was hydrolyzed in $5.7 \mathrm{~N} \mathrm{HCl}$ at $110^{\circ} \mathrm{C}$ for $1 \mathrm{~h}$, and the acid hydrolysate was electrophoresed as described previously (Sihag et al., 1999).

Cellular phosphorylation. To study cellular phosphorylation of SEPT5, $3 \mathrm{~d}$ in culture (3-DIC) primary rat embryonic day 18 (E18) cortical neurons were grown in $6 \mathrm{~cm}$ Petri dishes transfected with SEPT5 wild type or SEPT5 mutant (S327A). Twenty-four hours after transfection, the media were replaced with phosphate-free DMEM for $3 \mathrm{~h}$, and at $2.5 \mathrm{~h}$, one dish of transfected neurons with SEPT5 wild type was treated with 25 $\mu \mathrm{M}$ roscovitine. The cells were metabolically labeled with $300 \mu \mathrm{Ci}\left[{ }^{32} \mathrm{P}\right]-$ orthophosphate per dish and incubated for $3 \mathrm{~h}$. The neurons were then harvested by scraping into ice-cold lysis buffer containing $50 \mathrm{~mm}$ Tris$\mathrm{HCl}, \mathrm{pH}$ 7.5, $150 \mathrm{~mm} \mathrm{NaCl}, 1 \mathrm{~mm}$ EDTA, $0.1 \mathrm{~mm}$ sodium vanadate, 0.5 mu sodium fluoride, and $1 \%$ Triton X-100 supplemented with protease inhibitors (Complete; Roche). Equal amounts of cell lysates were used to immunoprecipitate SEPT5 with polyclonal septin 5 antibody (C-20). The antibody was captured with protein A-agarose beads, the beads were washed four times in lysis buffer, and the samples were prepared for SDS-PAGE. After SDS-PAGE and transfer to nitrocellulose membranes, ${ }^{32} \mathrm{P}$-labeled SEPT5 proteins were first visualized by autoradiography and then immunodetected by probing with mouse monoclonal septin 5 antibody (SP18).

Peptide mapping by reversed-phase HPLC. GST-Sept5 was phosphorylated in vitro by Cdk5/p35 in the presence of radioactive ATP. The ${ }^{32} \mathrm{P}$ - 
A

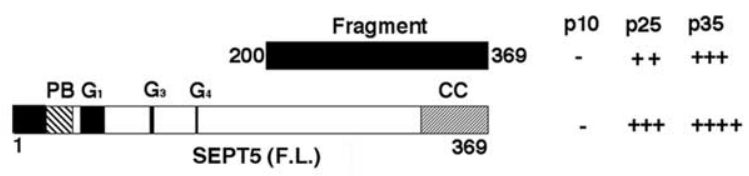

B

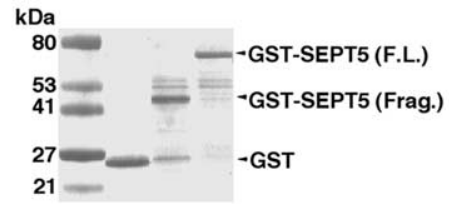

C

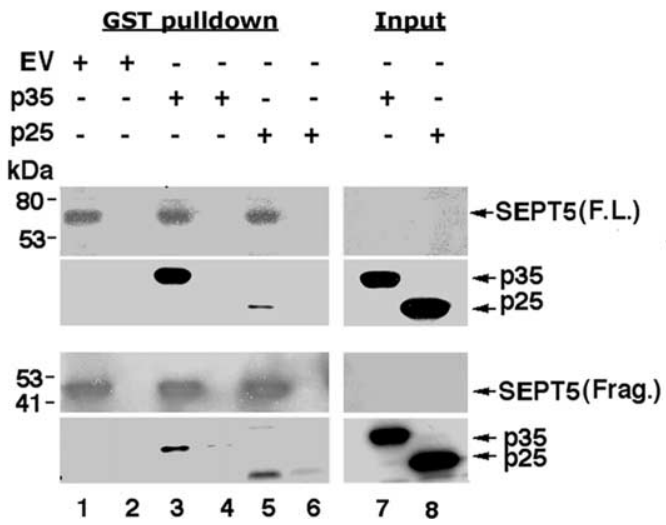

Figure 1. SEPT5 interacts with $\mathrm{p} 35$ in yeast two-hybrid screen and GST-pull-down assays. $\boldsymbol{A}$, SEPT5, a protein of 369 amino acid residues, contains a polybasic region (PB), G1, G3, and G4 GTP-binding sites in the GBD (GTP-binding domain), and a coiled-coiled domain (CC) at the $C$ terminus. The SEPT5 fragment that interacted with $\mathrm{p} 25$ in the yeast two-hybrid screen is shown as a black box above the SEPT5 F.L. comprising amino acid residues $200-369$. Yeast cotransformed with $p 35$ or with different domains of $p 35(p 10, p 25)$ and SEPT5 full length as well as the SEPT5 fragment (in activation domain vector pGADT7) were grown in media lacking tryptophan, leucine, and histidine containing $25 \mathrm{~mm} 3$-aminotriazole. $\beta$-Galactosidase assays were performed to test interactions and were judged by comparing the color generation of the positive control. Interaction strength is indicated as follows: ++++ , very strong; +++ , medium interaction; ++ , weak interaction. $B$, Coomassie blue stain shows expression of GST, GST-SEPT5 F.L., and GST-SEPT5 Frag. C, SEPT5 interacts with p35 and p25 in vitro in GST-pulldown assays. GST, GST-SEPT5 F.L., and GST-SEPT5 Frag. proteins were used as bait with CHO cell lysates transfected with empty vector (EV) (lanes 1, 2), p35 (lanes 3, 4), and p25 (lanes 5, 6). Samples were separated by SDS-PAGE and then probed with monoclonal septin 5 (SP18) antibody (first and third panels) and polyclonal p35 (C19) antibody (second and forth panels). Lanes 7 and 8 show the $\mathrm{CH} 0$ cell lysates transfected with p35 and p25, respectively, as control. Lanes 2,4 , and 6 show the pull-down assay with only GST protein.

labeled SEPT5 was resolved by SDS-PAGE and was transferred onto PVDF membranes and stained with Coomassie blue. The membrane with the SEPT5 band was cut into small pieces and washed sequentially with methanol and distilled water and then blocked with $1.5 \%$ poly(vinylpyrrolidone)-40 in $100 \mathrm{~mm}$ acetic acid. Membranes were digested with trypsin in $50 \mathrm{~mm} \mathrm{NH}_{4} \mathrm{HCO}_{3}, \mathrm{pH} 8$, overnight. The digest was lowered to $\mathrm{pH} 2$ with $20 \%$ trifluoroacetic acid and loaded onto a Waters $3.9 \times 300 \mathrm{~mm} \mathrm{C}_{18}$ column. Chromatography was performed in a Waters chromatography system with two 626 HPLC pumps, a 600 S controller, and a 996 photodiode array detector. The column was developed with an increasing gradient of acetonitrile in $0.05 \%$ aqueous trifluoroacetic acid. The stepwise gradient at a flow rate of $1 \mathrm{ml} / \mathrm{min}$ was $0-30 \% \mathrm{CH}_{3} \mathrm{CN}$ over $90 \mathrm{~min}, 30-60 \%$ for $5 \mathrm{~min}$, and $60 \%$ for $5 \mathrm{~min}$. One minute fractions were collected and Cerenkov counted for ${ }^{32} \mathrm{P}$ content in a Beckman (Fullerton, CA) LS 5801 scintillation counter.

Edman degradation. Semiautomated N-terminal sequence analysis was performed in an Applied Biosystems (Foster City, CA) 492 Sequencer. ${ }^{32} \mathrm{P}$-labeled peptides were covalently bound to Sequelon-AA discs and subjected to solid-phase Edman degradation with a model 492 Applied Biosystems peptide Sequencer. Each sequence cycle was collected onto a disc of Whatman (Clifton, NJ) filter paper, dried, and
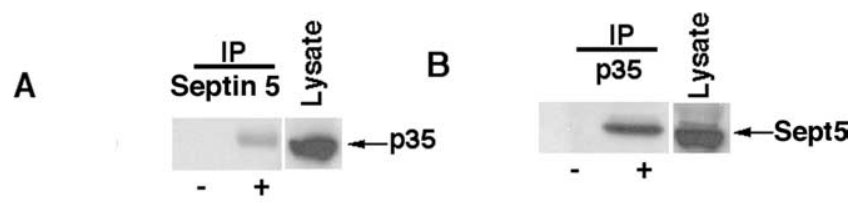

C

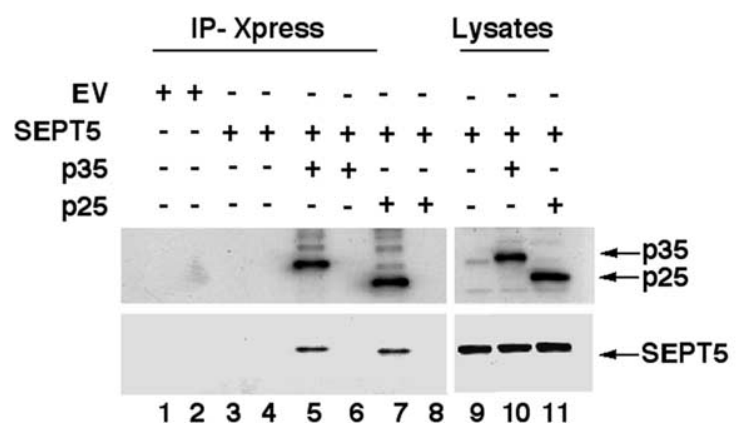

Figure 2. Septin 5 coimmunoprecipitates $\mathrm{p} 35$ from rat brain and transfected $\mathrm{CHO}$ cell lysates. $A$, Postnatal day 8 (PN8) rat brain lysate was immunoprecipitated with mouse monoclonal septin 5 antibody, and p35 was immunodetected in Western blots with polyclonal p35 antibody. $\boldsymbol{B}$, Rat brain lysate as above was immunoprecipitated with monoclonal p35 antibody, and the expression of septin 5 was confirmed using polyclonal septin 5 antibody. The presence of $p 35$ and septin 5 in rat brain lysate is shown using their respective antibodies as a positive control. The + and - signs are presence and absence of immunoprecipitating antibody, respectively. C, CHO cell lysates transfected with empty vector (EV) (lanes 1,2), SEPT5 alone (lanes 3, 4), p35/SEPT5 (lanes 5, 6) and p25/SEPT5 (lanes 7, 8) were immunoprecipitated with monoclonal anti-Xpress antibody. Western blots show the expression of p35 and p25 with polyclonal p35 antibody (top), and SEPT 5 was detected using polyclonal septin 5 antibody (bottom). Lanes $2,4,6$, and 8 mark the absence of immunoprecipitating antibody. Lanes 9,10 , and 11 show the expression of p35, p25, and SEPT5 in the whole-cell lysates, using their corresponding antibodies.

placed in a cassette with a screen. The screen is then examined for ${ }^{32} \mathrm{P}$ counts and quantitated using a Typhoon 9400 GE Healthcare phosphoimager.

Circular dichroism. Circular dichroism (CD) measurements were made in a Jasco (Tokyo, Japan) J-715 spectropolarimeter, using quartz cuvettes at room temperature (McPhie, 2001). Spectra were measured from 260 to $190 \mathrm{~nm}$, with four scans at $50 \mathrm{~nm} / \mathrm{min}$, time constant $=1 \mathrm{~s}$, bandwidth $=1 \mathrm{~nm}$, and slit width $=500 \mathrm{~mm}$. The instrument was continually flushed with nitrogen and was calibrated every 2 weeks with a solution of ammonium(D)-10-camphorsulfonate, using the two-point procedure of Chen and Yang (1997). For each protein ellipticity and photomultiplier voltage (high tension), baselines were measured using $200 \mu$ l of buffer in a $1 \mathrm{~mm}$ pathlength cuvette. Then an aliquot of freshly made protein solution was diluted into the buffer, to a concentration of $\sim 0.5 \mathrm{mg} / \mathrm{ml}$, and its CD spectra were measured.

Small interfering RNA transfection. Small interfering RNA (siRNA) transfection and assays in cortical neurons were performed as described previously (Zheng et al., 2007).

Synaptic vesicle preparation. Synaptic vesicles were isolated from adult rat brain using Synaptic Vesicles Isolation Kit from Sigma following the manufacturer's protocol based on the procedure described by Roz et al. (2002). Briefly, cortices from 10 rat brains were homogenized in homogenization buffer and referred to as "whole extract." The homogenate was centrifuged at $1500 \times g$ for $10 \mathrm{~min}$ to remove nuclei and cell debris, and the supernatant was saved. The pellet was washed once and centrifuged, and the combined supernatants were centrifuged again at $20,000 \times g$ for $20 \mathrm{~min}$. The pellet, referred to as P2, was homogenized in lysis buffer and incubated on ice for $45 \mathrm{~min}$. The homogenate was centrifuged at $20,000 \times g$ for $20 \mathrm{~min}$, and the supernatant containing the released synaptic vesicles was further centrifuged at $62,000 \times g$ for $40 \mathrm{~min}$. The pellet, enriched in synaptic vesicles, was homogenized in storage buffer, and is referred to as synaptic vesicle preparation (P3).

hGH secretion assay in PC12 cells. PC12 cells were plated on $35 \mathrm{~mm}$ plates (BD Biosciences) at a density of $5 \times 10^{5}$ cells $/ \mathrm{cm}^{2}$, were main- 
tained in RPMI-1640 with 5\% heat-inactivated FBS and $10 \%$ horse serum at $37^{\circ} \mathrm{C}$ in a $5 \% \mathrm{CO}_{2}$ humidified atmosphere. After $24 \mathrm{~h}$ cells were transiently transfected with the plasmid pXGH5 along with other constructs using the Fugene 6 transfecting reagent according to the manufacturer's instructions. The exocytosis assay protocol was based on that published by Sugita et al. (1999). All experiments were carried out in triplicate and repeated nine times. The amount of hGH was measured using hGH ELISA kit, and the secretion (percentage of total) is calculated as secreted $\mathrm{hGH} /($ secreted $\mathrm{hGH}+$ cellular $\mathrm{hGH}) \times 100$.

\section{Results}

SEPT5 interacts with $\mathrm{p} 35$ in

GST-pull-down assays

In our search for novel binding partners that interact with $\mathrm{p} 35 / \mathrm{Cdk} 5$, we performed a yeast two-hybrid screen using an adult human brain cDNA library. Because p25 contains a common protein-binding region (Wang et al., 2000), we chose p25 as bait in our yeast two-hybrid screen. Positive prey clones that supported growth on medium lacking histidine, leucine, and tryptophan were rescued and retransformed into fresh yeast cells with p25 bait or various control baits. The specificity of the bait and prey interactions was then confirmed by transactivation assays of induced $\beta$-galactosidase activity. One clone identified in the screen contained a cDNA insert encoding amino acid residues 200-369, corresponding to a C-terminal fragment of human septin 5.

The full-length SEPT5 contains GTP-binding sites near the N terminus and a predicted coiled-coil motif near the $\mathrm{C}$ terminus (Fig. 1A). To study the domains of interactions between bait and prey plasmid, p10, p25, and p35/pGBKT7 (GAL-4 DNA-binding domain) were cotransformed with SEPT5 full length and SEPT5 fragment/pGADT7 (GAL-4 DNA activation domain AD) into the yeast for $\beta$-galactosidase activity assay. As shown in Figure $1 A$, p10 did not interact with SEPT5 full length or its fragment, whereas both p25 and p35 showed interaction with SEPT5 full length and its fragment, which confirmed the initial screening results. Glutathione $S$-transferase (GST)-pull-down assays were performed to further validate the SEPT5-p35/p25 interaction found in the yeast two-hybrid screen. GST-SEPT5 full length and GST-SEPT5 fragment were expressed in Escherichia coli and purified and were subjected to SDS-PAGE to confirm the predicted molecular weights. The results in Figure $1 B$ show expression of GST, GST-SEPT5 fragment, and GST-SEPT5 full length at expected molecular weights. These three expressed proteins were immobilized on glutathione-Sepharose beads and used as bait in the GST-pull-down assays against lysates of CHO cells transfected with p 35 or p 25 (Fig. $1 C$ ). The data presented in Figure $1 C$ illustrate the interaction of p35 and p25 with GST-SEPT5 full length (top two panels) and GST-SEPT5 fragment (bottom two panels). The results show that GST-SEPT5 full length and GSTSEPT5 fragment interact with p35 and p25 from the transfected $\mathrm{CHO}$ cell lysates with $\mathrm{p} 35$ showing a strong interaction with the SEPT5 full length. Control GST protein alone (lanes 2, 4, and 6) exhibited no interactions with either p35 or p25, confirming specificity of the interactions. These in vitro binding results confirm the yeast two-hybrid data.

Septin 5 binds to $\mathrm{p} 35$ in the rat brain and transfected cells To gain further insight into the interaction between septin 5 and p35 in brain, we immunoprecipitated Sept 5 from rat brain lysates with monoclonal septin 5 antibody and immunodetected p35 with polyclonal p35 antibody (Fig. $2 \mathrm{~A}$ ). We also immunoprecipitated rat brain lysates with $\mathrm{p} 35$ monoclonal antibody and probed with polyclonal septin 5 antibody (Fig. $2 B$ ). The results of both IPs show that endogenous Sept 5 and p 35 coimmunoprecipitate from rat brain lysates, suggesting their interaction in vivo. A transfection assay was also performed to compare the association of p35 and p25 with SEPT5. SEPT5 full length was cloned into pCMV-Myc epitope-tagged vector and transfected alone or cotransfected with p35 or p25 into CHO cells (Fig. 2C). Both p35 and p25 were immunoprecipitated using an anti-Xpress antibody (Xpress is an epitope engineered into pcDNA 3.1C) and were immunodetected using a polyclonal p35 antibody (Fig. 2C, top). SEPT5 was immunodetected using a polyclonal septin 5 antibody (Fig. 2C, bottom). Note that SEPT5 was expressed in lanes 5 and 7, further confirming the association of SEPT5 with p35 and p25. The immunoblot of lane 3 did not show any interaction because the SEPT5 expression vector has a Myc-epitope, which did not form an immunocomplex with the anti-Xpress antibody. This confirms the binding of p35 and p25 with SEPT5 in transfected cells and the mammalian equivalence of this interaction found in yeast.

\section{Septin 5 colocalizes with p35 and Cdk5 in cortical neurons}

In previous studies with cortical neurons, localization of p35 has been shown in perikarya, cell membrane, along the axon, and in the growing tips of cultured neurons (Nikolic et al., 1996). To examine the cellular localization of Sept 5 with Cdk5/p35, immu- 
A

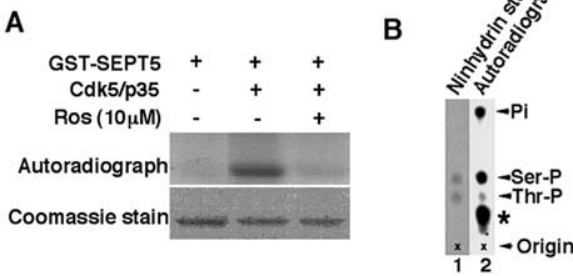

D

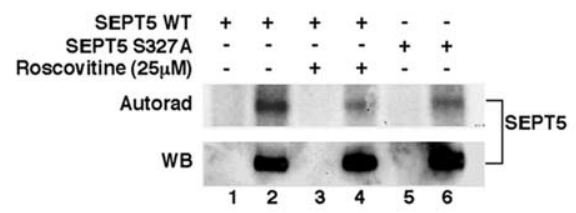

C

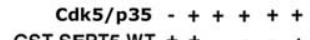

GST-SEPT5 WT + + - - - +

GST-SEPT5 S161A - + - -

GST-SEPT5S327A - . + - -

GST-SEPT5 S161A/S327A - - - - +

$\operatorname{Ros}(10 \mu \mathrm{M}) \ldots . .+$

Autorad

Coomassie stain
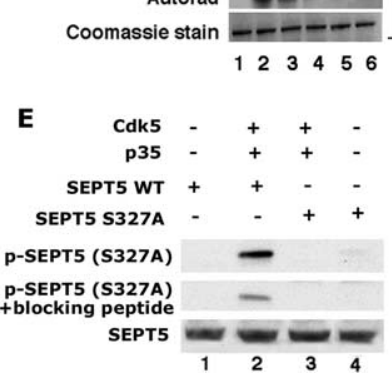

Figure 4. Phosphorylation of SEPT5 by Cdk5/p35. GST-SEPT5 protein was expressed and purified as described previously. Active $\mathrm{Cdk5}$ immunoprecipitated from rat brain lysate using $\mathrm{C} 8$ antibody or purchased from Millipore were used for phosphorylation assays. A, SEPT5 is phosphorylated by Cdk5/p35. Active Cdk5 immunoprecipitated from rat brain lysates phosphorylated GST-SEPT5 and was inhibited by $10 \mu \mathrm{m}$ roscovitine, a specific Cdk5 inhibitor. B, Phosphoamino acid analysis of SEPT5 phosphorylated by active $\mathrm{Cdk5/p35}$. The autoradiogram shows most incorporation of ${ }^{32} \mathrm{P}$ into $\mathrm{S}$ residues (lane 2 ). The asterisk in lane 2 denotes the band of undigested material. Pi refers to inorganic phosphate. Ninhydrin staining of the unlabeled $S$ phosphate and threonine phosphate mixed with the $5.7 \mathrm{~N} \mathrm{HCl}$ hydrolysate of [ $\gamma^{-}{ }^{32}$ P]ATP SEPT5 is also shown (lane 1). C, Serine 327 of SEPT5 is phosphorylated by Cdk5/p35. Kinase assays were performed with GST-SEPT5 WT (lane 2) and individually with GST-SEPT5 mutants (S161A, lane 3; S327/A, lane 4; S161A/S327A, lane 5) as substrates and active Cdk5/p35 as an enzyme. Bottom, Coomassie stain; top, the autoradiogram of the respective proteins. Lanes 1 and 6 show the phosphorylation of GST-SEPT5 WT without and with Cdk5/p35 plus roscovitine, respectively. D, Phosphorylation of SEPT5 by Cdk5/p35 in cortical neurons. Primary rat cortical neurons were transfected with SEPT5 WT and SEPT5 S327A mutant and metabolically labeled with [ $\left.{ }^{32} \mathrm{P}\right]-$ orthophosphate in the absence or presence of $25 \mu \mathrm{m}$ roscovitine. SEPT5 was immunoprecipitated with polyclonal septin 5 antibody with equal amounts of cell lysates, and Western blots were prepared. Top, Autoradiograph; bottom, the corresponding immunoblot to show the SEPT5 expression level with monoclonal septin 5 antibody. The results in lanes 2, 4, and 6 show the IPs in the presence of septin 5 antibody, and lanes 1, 3, and 5 show the IPs in the absence of septin 5 antibody. SEPT 5 WT phosphorylation is shown in lane 2. Lane 4 shows the SEPT5 WT phosphorylation in the presence of $25 \mu \mathrm{m}$ roscovitine, and SEPT5 mutant (S327A) phosphorylation is shown in lane 6. This experiment is an example of three independent experiments. $\boldsymbol{E}$, Phosphorylation of SEPT5 by Cdk5/p35 in HEK 293 cells. HEK 293 cells were transfected with empty vector (EV), SEPT5 WT, and SEPT5 mutant S327/A in the presence or absence of $\mathrm{Cdk5/p35}$. The lysates were immunoprecipitated with monoclonal septin 5 antibody, and the blots were immunodetected with site-specific polyclonal $\operatorname{Ser}(P)^{327}$ antibody (top), $\operatorname{Ser}(P)^{327}$ antibody plus blocking peptide (middle), and polyclonal septin 5 antibody (bottom). The results of transfected HEK 293 cells are shown as SEPT5 WT alone (lane 1); SEPT5 WT plus Cdk5 and p35 (lane 2); SEPT5 mutant (S327A) plus Cdk5 and p35 (lane 3); and SEPT5 mutant (S327A) alone (lane 4).

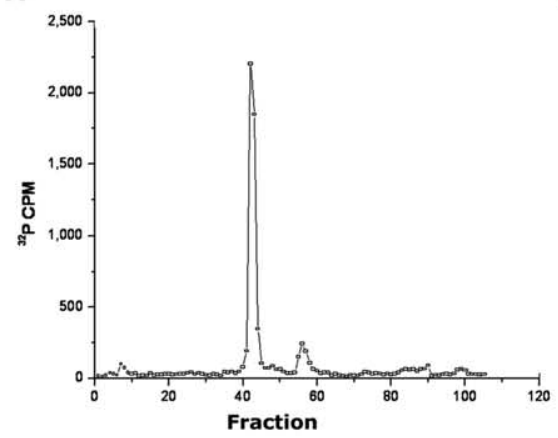

B

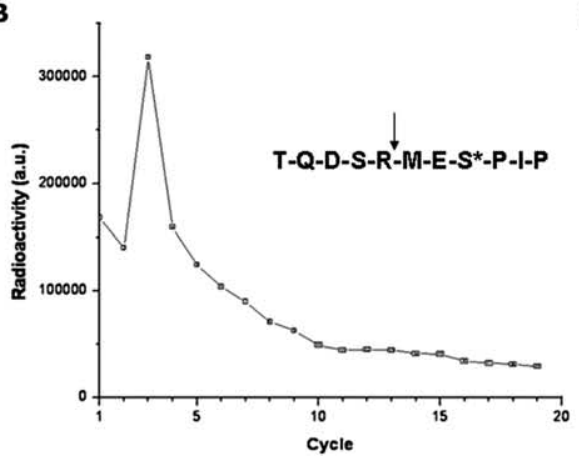

3). The top panel shows colocalization of Sept5 with p35 $(a-c)$, whereas the bottom panel shows Sept5 and Cdk5 colocalization. Note that Sept5 is expressed in neurites and at the periphery of the cell body, whereas p 35 and Cdk5 are more diffusely distributed over the cell body and neurites. In the overlay image, colocalization can be seen in the neurites and in the cell periphery, particularly intense at specific sites at the base of neurites ( $c, f$, small arrows). This is true for both p35 and Cdk5 and suggests that endogenous Sept 5 colocalizes in specific cellular regions with the endogenous Cdk5 complex.

\section{Cdk5/p35 phosphorylates SEPT5}

Because SEPT5 was identified as a p35binding protein, we wanted to determine whether it is a substrate of Cdk5. In initial experiments, active Cdk5 was immunoprecipitated from rat brain lysates and shown to phosphorylate GST-SEPT5. This was inhibited by roscovitine, an inhibitor of Cdk5 (Fig. 4A). Active Cdk5/p35 (Millipore) showed identical results and was used in all subsequent experiments. To identify the Cdk5 phosphorylation site(s) on SEPT5, we performed an analysis of ${ }^{32} \mathrm{P}$-phosphate radiolabeled phosphoamino acids. The phosphoamino acid analysis showed that most of the ${ }^{32} \mathrm{P}$ phosphate was incorporated into serine residues (Fig. 4B), indicating that the major Cdk5 phosphorylation site(s) on SEPT5 was a serine residue. A consensus sequence analysis of likely Cdk5 phosphor-

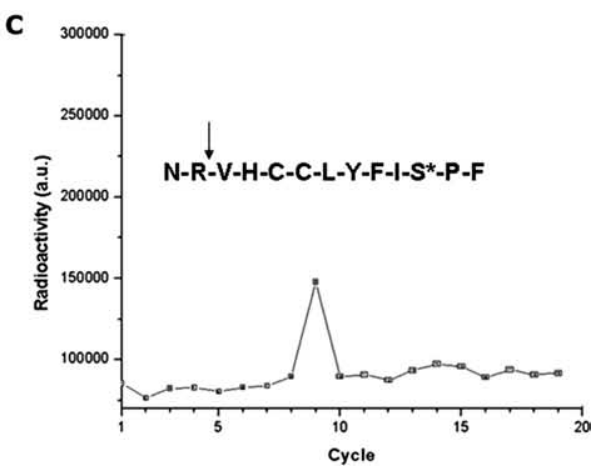

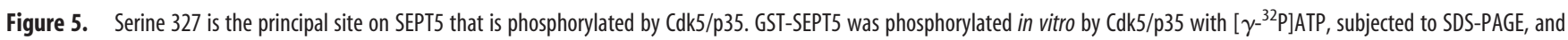
transferred to a PVDF membrane. The radioactive band was removed and digested with trypsin. $A$, The tryptic fragments were run through HPLC and the radioactivity assayed in each fraction. The fraction 42 , showing peak activity, and the minor fraction at $55-58$ were collected and subjected to Edman degradation sequence analysis. Sequence mapping was based on a procedure (Guszczynski et al., 2006) in which sequence cycles are collected as spots on filter papers in a microtiter plate and assayed for radioactivity. $\boldsymbol{B}$, In the third cycle, the ${ }^{32}$ P signal is derived from a serine 3 residue from the $\mathrm{N}$-terminal end of the tryptic peptide. The insert sequence shows the tryptic digestion site (arrow), and note that the phosphorylated $S(*)$ at the third residue from the $\mathrm{N}$-terminal end is $\mathrm{S} 327$. C, At the ninth cycle where activity is significantly lower, the ${ }^{32}$ Psignal marks a serine 9 residue from the $\mathrm{N}$-terminal end of the tryptic peptide. The sequence in the insert, representing the only SEPT5 sequence satisfying this criterion, is shown with the tryptic digest site at the arrow, and the $S^{*}(S 161)$, the ninth residue from the N-terminal end of the peptide.

nocytochemical assays were performed on E18 rat cortical neurons cultured for $7 \mathrm{~d}$. A rhodamine-conjugated secondary antibody was used to show Sept5 expression, and Oregon green secondary antibody was used for p 35 and Cdk5, respectively (Fig. ylation sites on SEPT5 indicated that residues S161 and S327 met the minimum consensus requirements for proline-directed kinases. To determine which of these sites is the most likely target for Cdk5, each site was mutated from serine to alanine as SEPT5 
S161A and SEPT5 S327A. We also mutated both sites from serine to alanine, SEPT5 S161A/S327A, to form the double mutant. In a phosphorylation assay with an active Cdk5/p35, mutant SEPT5 (S327A) and SEPT5 (S161A/S327A) showed almost no incorporation of ${ }^{32} \mathrm{P}$-phosphate compared with the wild-type SEPT5 (Fig. 4C, compare lanes 4 and 5 with lane 2). The incorporation was equivalent to that seen in the presence of the Cdk5 inhibitor, roscovitine (lane 6). The SEPT5 S161A mutant also showed incorporation of ${ }^{32} \mathrm{P}$-phosphate but at a reduced level compared with wild type (lane 3 ). These results suggest that S327 is the principal site of phosphorylation by $\mathrm{Cdk} 5 / \mathrm{p} 35$, and phosphorylation obtained in S161 could be attributed to phosphorylation at the accessible S327 site. Evidently, both sites are phosphorylated by Cdk5/p35, with the S327 site acting as a principal substrate target. It should be noted that a mouse septin 5 isoform 1 (adult-type Sept5_v1) derived from a rodent brain synaptosomal preparation was shown to be phosphorylated by Cdk5/p35 at S17 in the N-terminal region (Taniguchi et al., 2007). The amino acid sequence analysis shows that S17 is not present in human septin 5 (SEPT5), which is similar to the mouse fetal-type septin 5 isoform 2 (Sept5_v2) (Taniguchi et al., 2007). Supplemental Figure S1 (available at www. jneurosci.org as supplemental material) shows a sequence comparison of various septin 5 isoforms, human, mouse fetal, and mouse adult. Included are the respective Cdk5 phosphorylation sites that we have identified and the one identified by Taniguchi et al. (2007). It should be noted that the one site in the mouse adult Sept5 (S336), corresponding to the S327 site in human SEPT5, was not phosphorylated by Cdk5 (Taniguchi et al., 2007).

To determine whether Cdk5/p35 phosphorylates SEPT5 in vivo at S327, E18 rat cortical neurons transfected with SEPT5 wild type or SEPT5 mutant (S327A) were metabolically labeled with $\left[{ }^{32} \mathrm{P}\right]$-orthophosphate in the presence or absence of 25 $\mu \mathrm{M}$ roscovitine. The results are shown in Figure $4 D$. In autoradiographs, treatment of cells with roscovitine induced a marked reduction in the incorporation of ${ }^{32} \mathrm{P}$ labeled phosphate into SEPT5 (lane 4), which is consistent with a direct phosphorylation of SEPT5 WT by Cdk5/p35 (lane 2). Neurons transfected with mutant S327A also showed a marked reduction in phosphorylation (lane 6). The phosphorylation seen in lane 6 may be attributed to phosphorylation at $\mathrm{S} 161$ of the mutant protein. This is consistent with the hypothesis that $\mathrm{Cdk} 5$ phosphorylates SEPT5 at S327 in vivo in cortical neurons. To address the physiological relevance of Cdk5 phosphorylation of SEPT5 at S $^{327}$, we accumulations.
B
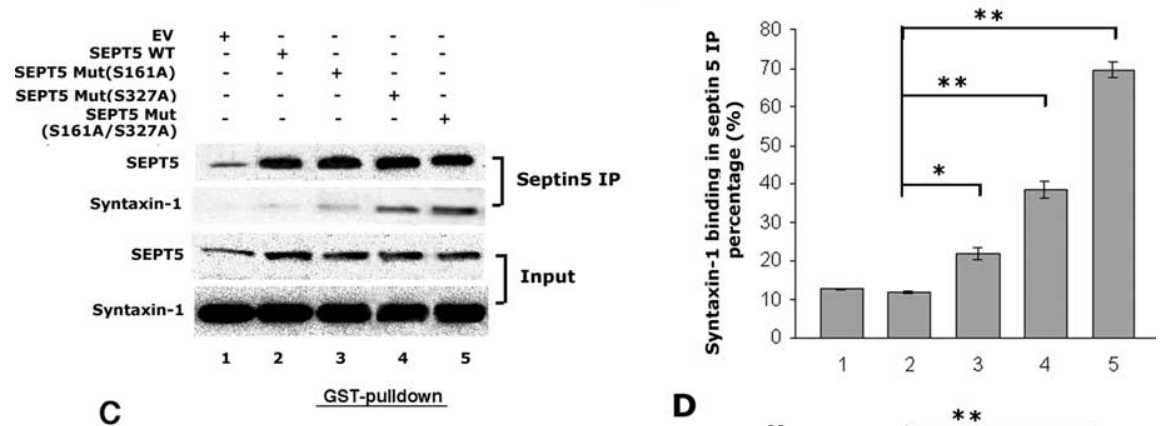

D

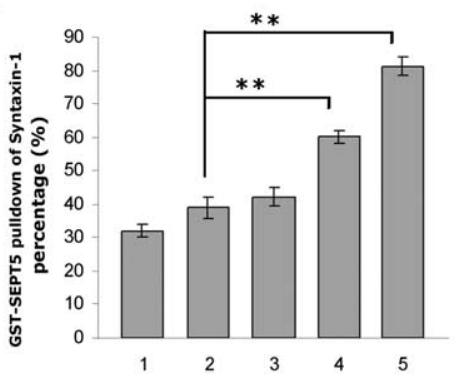

Figure 6. Mutation of SEPT5 (S327A) enhances binding to syntaxin-1. A, SEPT5 WT and SEPT5 mutants (S161A, S327A, and S161A/S327A) bind with syntaxin-1. 3-DIC cortical neurons were transfected with wild-type SEPT5 or SEPT5 mutants, S161A, S327A, and the double mutant S161A/S327A. Twenty-four hours after transfection, SEPT5 was immunoprecipitated from equal amounts of lysate with a polyclonal septin 5 antibody, and Western blots were prepared. The presence of SEPT 5 was confirmed using monoclonal SEPT5 antibody (first panel). Syntaxin- 1 was immunodetected with monoclonal syntaxin- 1 antibody (second panel). The third and fourth panels show the presence of SEPT5 and syntaxin- 1 in the whole-cell lysates. Robust binding of syntaxin- 1 is shown by the single mutant S327A and double mutant S161A/S327A in lanes 4 and 5 of the second panel. $\boldsymbol{B}$, The bar graph shows the percentage of the syntaxin- 1 binding to SEPT5 in the septin 5 IP. Data represent the mean of three separate experiments, and error bars represent the \pm SEM. ${ }^{*} p<0.01$, ${ }^{* *} p<0.001$, values indicate significant differences from WT. $\boldsymbol{C}$, Nonphosphorylated SEPT5 mutants bind syntaxin- 1 more effectively than the Cdk5/p35 phosphorylated wild type in GST-pulldown assays. Equal amounts of GST-SEPT5 WT or GST-SEPT5 mutant (S161A, S327A, and S161A/S327A) proteins on glutathioneSepharose beads were phosphorylated in the presence of active $C \mathrm{dk} 5 / \mathrm{p} 35$ in the kinase reaction buffer with cold ATP and used as bait with rat brain cortical neuron lysates. Samples were run by SDS-PAGE and immunoblotted with syntaxin-1 antibody (top) and reprobed with monoclonal septin 5 antibody (bottom). The interaction of syntaxin-1 with phosphorylated SEPT5 WT or SEPT5 mutants (S161A, S327A, and S161A/S327A) is shown in lanes 2, 3, 4, and 5, respectively. Lane 1 shows the GST-pull-down with GST protein alone. $\boldsymbol{D}$, The bar graph shows the percentage of the syntaxin-1 bound to SEPT5 in the GST-SEPT5 pull-down. Data represent the mean of three separate experiments, and error bars represent the \pm SEM. ${ }^{* *} p<0.001$ indicates significant difference. The bar graph shows mean density measurement of the syntaxin-1 binding in GST-SEPT5 pull-down. Results are expressed as mean \pm SEM of three separate experiments. $\boldsymbol{E}$, CD spectroscopy of the wild-type and S327A SEPT5 fusion proteins. The spectra were scanned from 190 to $250 \mathrm{~nm}$ and represented as mean residue ellipticity. All the spectra are averages of four

raised an antibody specific to phosphorylated $S^{327}$ [anti$\operatorname{Ser}(\mathrm{P})^{327}$ ]. Figure $4 E$ shows phosphorylation of SEPT5 at $\mathrm{S}^{327}$ in HEK 293 cells and the specificity of the anti-Ser $(\mathrm{P})^{327}$ antibody. The results in the second lane of Figure $4 E$ clearly show in vivo phosphorylation of SEPT5 at S327 when transfected along with $\mathrm{Cdk} 5 / \mathrm{p} 35$, and the level of phosphorylation was reduced in the presence of anti-Ser $(\mathrm{P})^{327}$-blocking peptide. SEPT5 S327A did 
Table 1. Secondary structural elements of SEPT5 wild-type and S327A mutant proteins as calculated from their respective $C D$ spectra

\begin{tabular}{lrr}
\hline Secondary structure & \multicolumn{1}{l}{$\begin{array}{l}\text { Wild type } \\
\text { (SEPT5) }\end{array}$} & \multicolumn{1}{c}{ S327A } \\
\hline$\alpha$-Helix & $7.0 \pm 0.3$ & \multicolumn{1}{c}{ SEPT5 } \\
$\beta$-Sheet & $28.1 \pm 6.5$ & $29.6 \pm 0.3$ \\
Turn & $34.5 \pm 4.2$ & $32.6 \pm 4.4$ \\
Coil & $30.4 \pm 3.0$ & $30.4 \pm 3.2$ \\
\hline
\end{tabular}
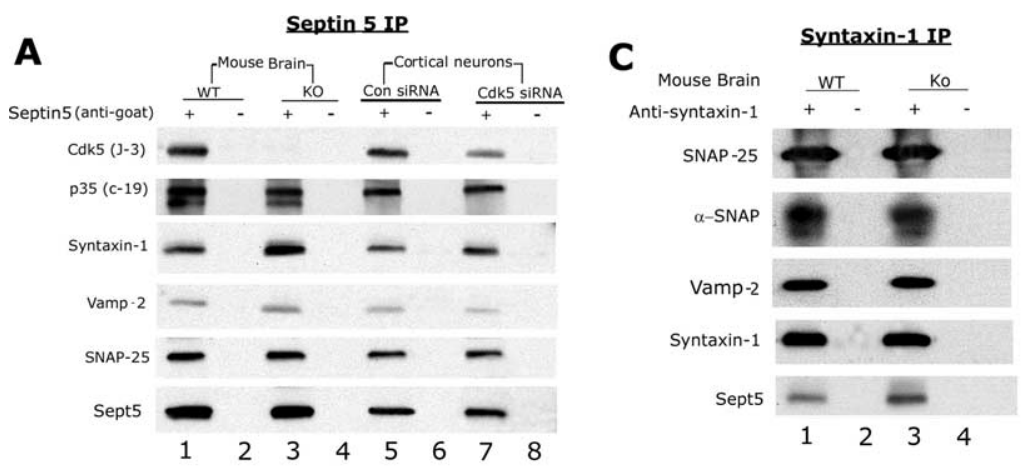

B

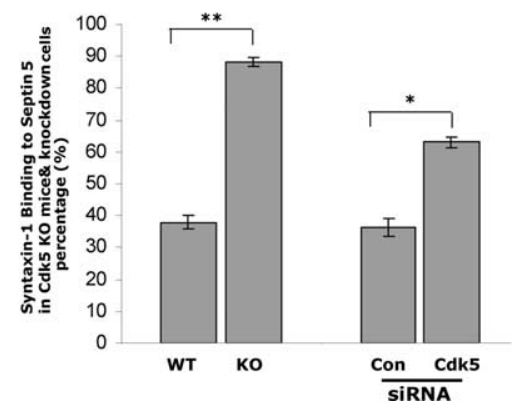

Figure 7. Endogenous phosphorylation of septin 5 by Cdk5/p35 reduced binding to syntaxin-1. A, Lysates of Cdk5 WT and Cdk5 $\mathrm{K} 0$ embryonic (E16) mouse brains and lysates from siRNA transfected (E18) rat cortical neurons were immunoprecipitated with polyclonal septin 5 antibody, and precipitates were analyzed by SDS-PAGE and Western blotting. Blots were then developed with antibodies specific to the proteins indicated to the left. Endogenous syntaxin binding to Sept 5 is reduced by Sept 5 phosphorylation in both cases. Exposures for SNAP-25 and Vamp-2 were considerably longer than for septin 5 and syntaxin-1, suggesting that the former SNARE proteins bound to septin 5 indirectly via direct association with syntaxin-1. $\boldsymbol{B}$, The bar graph shows the percentage of the syntaxin- 1 binding to Sept 5 in septin 5 IP. Data represent the mean of three separate experiments, and error bars represent the \pm SEM. ${ }^{*} p<0.01$, significantly different from control; ${ }^{* *} p<0.001$, significantly different from WT. C, Cdk5 WT and K0 mouse brain lysates were each immunoprecipitated with monoclonal syntaxin- 1 antibody, and the blots were analyzed with antibodies specific to the proteins indicated to the left. Here, in contrast to $A$, exposure times were the same for all proteins.

not react with anti-Ser $(\mathrm{P})^{327}$ antibody when coexpressed with Cdk5/p35 (Fig. 4E, lane 3). These results indicate that anti$\operatorname{Ser}(\mathrm{P})^{327}$ antibody specifically recognizes SEPT5 phosphorylated at $S^{327}$. To summarize, we see that p35 binds to SEPT5 in a number of biochemical assays; together with Cdk5, it colocalizes with Sept 5 in cortical neurons and phosphorylates SEPT5 both in vitro and in vivo at $\mathrm{S} 327$, a principal target site.

\section{Cdk5/p35 phosphorylates SEPT5 on S327}

We have shown in Figure 4 that SEPT5 is phosphorylated robustly by Cdk5/p35 at S327 and less efficiently at S161. To independently confirm these results by reversed-phase HPLC and Edman degradation to map phosphorylation sites, we used GSTSEPT5 wild type, phosphorylated by active Cdk5/p35 in the presence of $\left[\gamma_{-}{ }^{32} \mathrm{P}\right]$ ATP. The labeled SEPT5 was resolved by SDSPAGE, transferred to a membrane, stained with Coomassie blue, cut out, and cleaved with trypsin. The sites were identified using a new procedure for Edman degradation sequencing (Guszczyn- ski et al., 2006). The results are shown in Figure 5. Separation of the tryptic fragments by HPLC showed that fraction 42 contained most of the radiolabeled residues, and other fractions (55-58) ontained less of the radiolabeled residues, suggesting more than one phosphorylated peptide (Fig. 5A). When peptides from fraction 42 and fractions 55-58 were subjected to Edman degradation, ${ }^{32} \mathrm{P}$ was released at sequence cycle 3 (Fig. $5 B$ ) and cycle 9 (Fig. 5C), respectively. This means that the ${ }^{32} \mathrm{P}$ signal in the first case was obtained at the third residue from the tryptic peptide cleavage site. Only three serines in the SEPT5 sequence meet this requirement, and only the one shown in Figure $5 B, \mathrm{~S} 327$, is in a Cdk5 consensus motif. The peak at cycle 9 shows lower activity than that shown in cycle 3 (Fig. 5C). Here, only serine at 161 shown in Figure $5 C$ is part of a Cdk5 consensus sequence. Thus, these results confirm that S327 is the major site phosphorylated by Cdk5/p35 in SEPT5, whereas S161 is a minor site.

\section{Effect of Cdk5/p35 phosphorylation of} SEPT5 on its interaction with syntaxin-1 Septin 5 associates predominantly with the membrane-enriched fractions of brain, is colocalized with synaptic vesicles, and, during secretion, binds to syntaxin at the same site bound by SNARE proteins Vamp-2 and SNAP-25 (Beites et al., 1999). A mutation of septin 5 in the GTP-binding domain bound more efficiently to syntaxin-1 than the wild type and enhanced secretion of hGH (human growth hormone). Because p35 and Cdk5 are also enriched in nerve terminals, does Cdk5 phosphorylation of SEPT5 affect its association with syntaxin? To answer this question, E18 rat cortical neurons were transfected with SEPT5 wild type or SEPT5 mutants (S161A, S327A, and S161A/ S327A), and lysates were immunoprecipitated with polyclonal septin 5 antibody. The first panel in Figure $6 A$, probed with monoclonal septin 5 antibody, shows the expression of total SEPT5 wild type and mutants. Binding to syntaxin-1 in the same immunoprecipitates is revealed with syntaxin- 1 antibody (second panel). The quantitative results in Figure $6 \mathrm{~B}$ clearly show that the S327A and S161A/ S327A mutants displayed increased binding with syntaxin-1 (lanes 4 and 5, respectively), whereas SEPT5 WT and S161A mutant exhibit minimal binding (lanes 2 and 3, respectively). Because WT and S161A SEPT5 are phosphorylated by Cdk5/p35 (Fig. 4C), the results suggest that Cdk5 phosphorylation of SEPT5 decreases the binding of SEPT5 to syntaxin-1.

We corroborated these results using phosphorylated GST fusion proteins of SEPT5 wild type and SEPT5 mutants (S161A, S327A, and S161A/S327A) immobilized on glutathione Sepharose beads and incubated with equal amounts of cortical neuron lysates. The results of a GST-pull-down assay (Fig. 6C) show the interactions of syntaxin-1 with wild-type and mutant GST fusion proteins as revealed with syntaxin- 1 antibody (top). The bottom panel shows the expression of SEPT5 with septin 5 antibody. GST protein alone did not pull down syntaxin-1 as shown in lane 1 . 


\section{Septin 5}
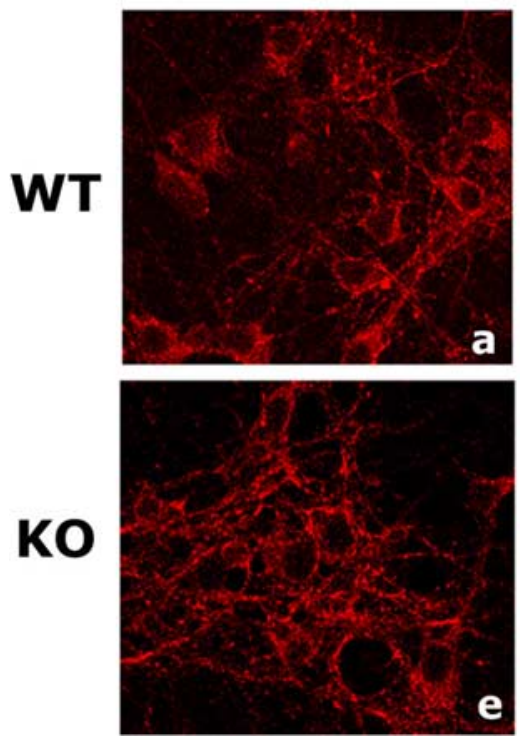

Syntaxin-1
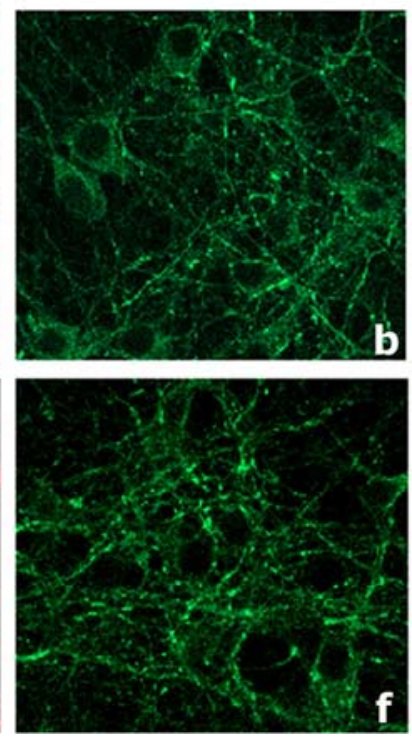

DAPI
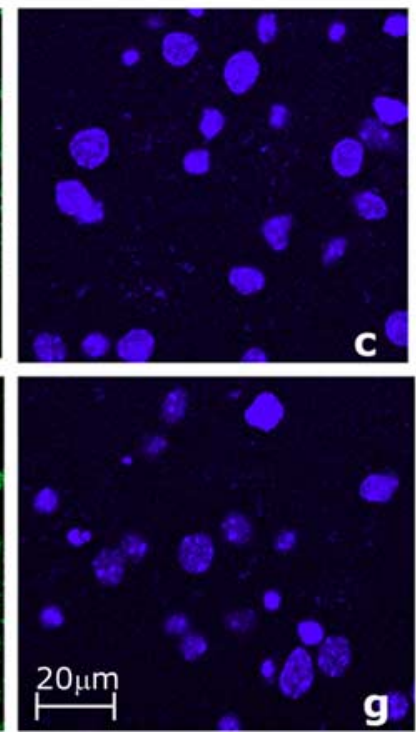

g
Overlay
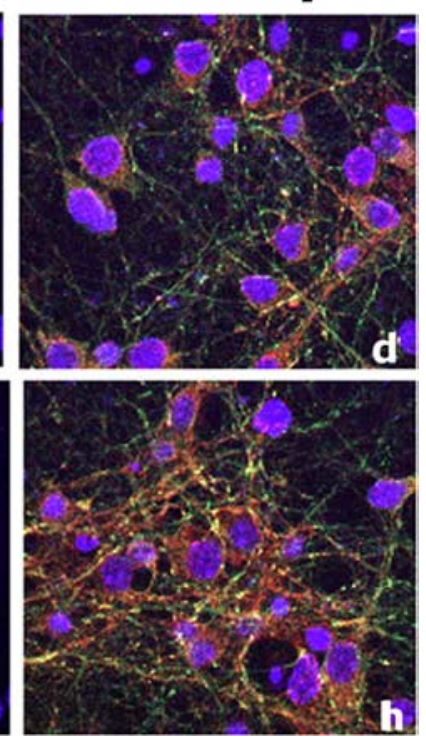

Figure 8. Septin 5 colocalizes with syntaxin-1 in putative synapses of Cdk5 WT and Cdk5 K0 mouse cortical neurons. $\boldsymbol{a}$ - $\boldsymbol{h}, 10$-DIC E15 mouse cortical neurons were immunostained to detect endogenous Sept5 with syntaxin-1 in Cdk5 WT (a-d), and Cdk5 KO (e- $\boldsymbol{h})$. Sept5 was immunostained using polyclonal septin 5 antibody and visualized with Texas Red ( $\boldsymbol{a}, \boldsymbol{e})$; syntaxin-1 was immunostained using monoclonal syntaxin-1 antibody $(\boldsymbol{b}, \boldsymbol{f})$ and was visualized using Oregon Green. The overlay shows the colocalization in yellow $(\boldsymbol{d}, \boldsymbol{h})$. Scale bar, $20 \mu \mathrm{m}$.

The densitometric analyses in Figure $6 \mathrm{D}$ confirm that nonphosphorylated SEPT5 (S161A/S327A) and the partially phosphorylated S327A (phosphorylated at S161) bind syntaxin-1 more efficiently than the wild type (presumably phosphorylated at both sites). It should be noted that S161 lies within the GTP domain of SEPT5, which when mutated increased syntaxin-1 binding (Beites et al., 1999) and is part of the N-terminal truncated fragment of SEPT5 that exhibited maximum syntaxin-1 binding (Beites et al., 2005). Nevertheless, phosphorylation at S327 in the SEPT5 $161 \mathrm{~A}$ mutant is sufficient to significantly reduce binding equivalent to that of the wild type (Fig. $6 D$, compare lanes 2, 3). Clearly, $\mathrm{S} 327$ is the site whose modulation by Cdk5/P35 phosphorylation has a more profound effect on SEPT5 binding to syntaxin-1 and, presumably, may also affect syntaxin function at the synapse.

The question arises as to whether the mutant and wild-type septin proteins have the same secondary structures. It could be argued that the observed change in the binding activity of SEPT5 mutant (S327A) is caused by perturbations in the secondary structure of the protein. Far-UV circular dichroism spectroscopic analysis, however, suggests that WT and mutant (S327A) have similar secondary structures (Fig. 6E). The CD spectra of the mutant protein were similar to wild-type SEPT5. The number of secondary structural elements of wild-type and mutant proteins was calculated by K2D software and shown in Table 1. No major differences in the percentage of $\alpha$-helices, $\beta$-sheets, turns, or coils between the mutant and wild-type proteins were observed, suggesting that the change in binding capacity is not caused by any major secondary structural alterations.

Septin 5 interaction with syntaxin-1 in cortical neurons of Cdk5 wild-type and knock-out mice and in Cdk5 siRNAtransfected cortical neurons

To establish further that phosphorylation of septin 5 by Cdk 5 affects binding of endogenous syntaxin-1 and to determine whether this affects other SNARE proteins, we immunoprecipitated brain lysates from Cdk5 WT and knock-out (KO) mice with polyclonal septin 5 antibody and subjected immunoprecipitates to Western blot analysis. It was assumed that in the WT neurons, septin 5 would be phosphorylated by Cdk5/p35. In Figure $7 A$, the SNARE antibodies used to probe the blots are indicated on the left. Similar experiments in cortical neurons in which Cdk5 activity was reduced by transfected siRNA are also included in Figure $7 A$. In the $\mathrm{KO}$ experiments (first two vertical panels), the results show increased binding of syntaxin-1 with Sept 5 in the Cdk5 KO samples (compare lanes 1, 3) but this did not affect other SNARE proteins, and similar results were obtained in the Cdk5 knock-down cultured cells (lanes 5, 7), where one can see a significant reduction in the expression of Cdk5 (first panel, lane 7 ). The results of the histogram in Figure $7 B$ suggest that endogenous phosphorylation of Sept 5 by Cdk 5 at both sites, S161 and S327, each one occupying one of the two syntaxin-binding sites (Beites et al., 2005), does reduce the percentage of syntaxin-1 binding to Sept5 without affecting the binding of SNARE proteins. It should be noted that the expressions of SNAP-25 and Vamp-2 required overexposure because it has been shown that neither binds directly to septin 5 , but both bind indirectly via syntaxin-1 (Beites et al., 2005). The results with transfected cdk5 siRNA are similar; the resulting reduced levels of cdk5 expression correlate with significantly increased binding of syntaxin-1 to septin 5 [Fig. 7A (compare lanes 5, 7), B (right-hand bars)]. Endogenous nonphosphorylated septin 5 binds more efficiently to syntaxin-1 than septin 5 phosphorylated by Cdk5.

In the reciprocal syntaxin-1 immunoprecipitation of brain lysates from Cdk5 WT and KO mice, SNARE protein antibodies as indicated were used to determine the effect of phosphorylation of Sept 5 on the interaction of SNARE proteins with syntaxin-1. The results in Figure $7 C$ show significantly increased binding of nonphosphorylated Sept5 with syntaxin-1 in the KO samples (fifth panel, lane 3) without affecting the binding of other SNARE proteins to syntaxin-1. In this experiment, all blots were equally exposed. Interactions of $\mathrm{nSec} 1$ or phospho-nSecl with syntaxin may also interfere with syntaxin binding to septin 5 and/or SNARE proteins (Beites et al., 2005).

To demonstrate the colocalization of septin 5 with syntaxin-1 
A

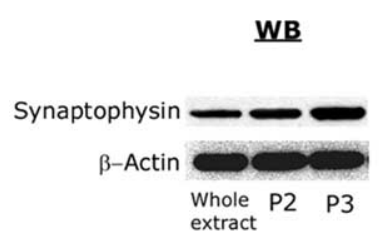

C

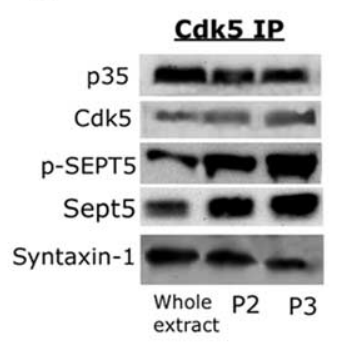

E

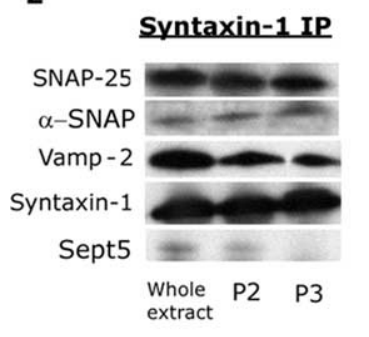

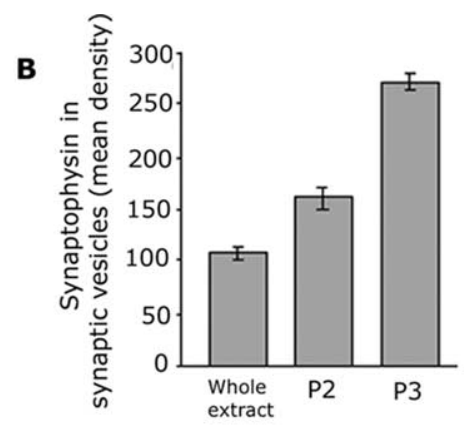

D

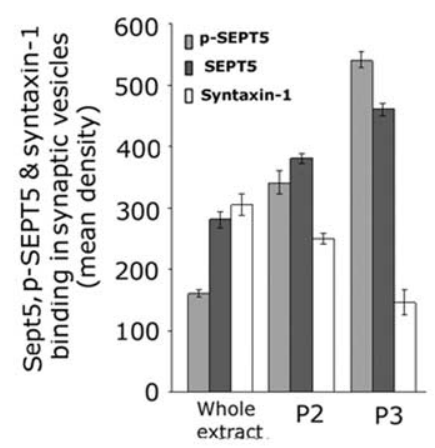

$\mathbf{F}$

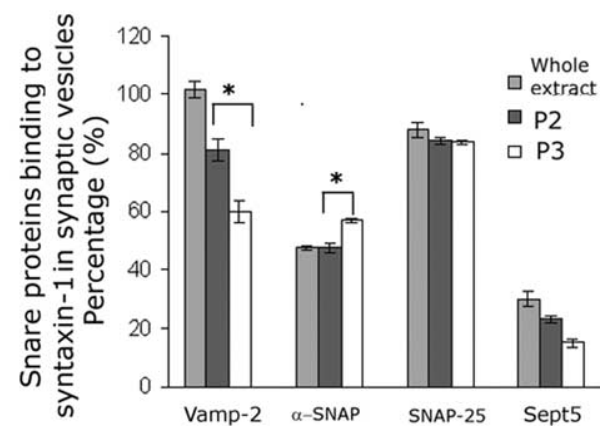

Figure 9. C C dk5/p35 phosphorylation of septin 5 in a rat brain synaptic vesicle fraction decreases syntaxin- 1 binding. Cortices from 10 adult rat brains were isolated, homogenized, and processed for an enriched synaptic vesicle fraction using a Sigma kit (SV0100) based on a procedure published by Roz et al. (2002). Three fractions were used for immunoprecipitation studies, the initial whole extract, a P2 crude synaptosome fraction, and P3, purified synaptic vesicles (see Materials and Methods). The course of the purification was monitored by Western blots for synaptophysin, a key synaptic vesicle protein. $\boldsymbol{A}$, Western blots for synaptophysin in each fraction showed a progressive increase in expression as seen in the histogram in $\boldsymbol{B}$. Actin was used as a measure of protein loading. C, A C dk5 monoclonal antibody (J3) was used to immunoprecipitate the three fractions, and the immunoprecipitates were probed with polyclonal antibodies to p35, Cdk5, phospho-SEPT5 $\left[\operatorname{Ser}(\mathrm{P})^{327}\right]$, septin 5 , and syntaxin-1 (H-221). As Sept5 phosphorylation increased in the vesicle enriched fractions, syntaxin-1 binding to the Cdk5 complex declined significantly. D, A histogram of a quantitative analysis of three experiments showing the increasing levels of phospho-SEPT5 and Sept5 expression in the more purified fractions, P2 and P3, and the accompanying decline in syntaxin- 1 expression. $\boldsymbol{E}$, Using a monoclonal syntaxin-1 antibody (HPC-1), each fraction was immunoprecipitated and probed with rabbit polyclonal antibodies to syntaxin-1, SNAP-25, and Vamp-2 and a polyclonal antibody to septin 5. F, A histogram analysis of percentage binding to syntaxin-1 in three experiments showed in the P3 fraction a weak binding of Sept 5 to syntaxin-1, a significant increase in binding of $\alpha$-SNAP to syntaxin- 1 , and a decreased binding of Vamp- 2 to syntaxin- 1 in P3 ( ${ }^{*} p<0.01$ ). SNAP-25 binding to syntaxin-1 remained relatively unchanged during the purification.

in newly developed synapses in cortical neurons of Cdk5 wildtype and knock-out mice, we cultured cells for $10 \mathrm{~d}$ (to promote synapse formation) and performed immunocytochemistry as shown in Figure 8 . The results of overlay (compare $d, h$ ) clearly show more extensive binding of septin 5 to syntaxin- 1 in putative developing synapses of Cdk5 KO cortical neurons than in the Cdk5 WT cells. This is consistent with the in vitro data showing greater binding of the mutant nonphosphorylated septin 5 to syntaxin- 1 than the WT.
Although our emphasis is on the role of septin 5 interactions with syntaxin- 1 in the SNARE complex and its effect on exocytosis, the availability of WT and Cdk5 KO cortical neurons expressing elaborate synaptic contacts made it possible to examine whether septin 5 colocalizes with synapsin, a vesicle protein, to determine whether septin 5/synapsin binding is also dependent on Cdk5/p35 phosphorylation of septin 5. The results of these ICC experiments are shown in supplemental Figure S2 (available at www.jneurosci.org as supplemental material). The overlay $(d, h)$ clearly shows more binding of septin 5 to synapsin in putative synapses of Cdk5 knock-out cortical neurons, suggesting that at the level of the vesicle, Cdk5 phosphorylation of septin 5 may also play an important role in modulating vesicle interaction with the SNARE complex.

Cdk5/p35 phosphorylation of septin 5 in enriched synaptic vesicle preparations affects its binding to syntaxin-1

Using a commercial procedure for synaptic vesicle preparation based on that published by Roz et al. (2002), adult rat cortices were processed into three distinct fractions, the original whole extract, a P2 synaptosome fraction of mixed membranes and vesicles, and a P3 fraction of purified synaptic vesicles. To monitor the purification, each fraction was analyzed by Western blotting using a monoclonal antibody to synaptophysin, a key synaptic vesicle protein (Fig. 9A). The histogram in $9 B$ indicates the increased enrichment of synaptophysin-bearing synaptic vesicles in P3. To determine whether Cdk5/p35 is found in these fractions, a polyclonal Cdk5 antibody was used to immunoprecipitate each fraction and probed with antibodies to septin 5, p-SEPT5 [Ser $(\mathrm{P})^{327}$ specific], syntaxin-1, p35, and Cdk5 as shown in Figure $9 C$. Note that both Sept 5 and p-SEPT5 are significantly enriched in the synaptic vesicle fraction, whereas syntaxin-1 binding to Cdk5 decreased. The results are quantified in the histogram in $9 D$ and are based on three experiments. In view of our previous results, this reduction in syntaxin-1 binding is predicted in view of the increased phosphorylation of SEPT5 at S327. The results indicate that Cdk5 and septin 5 form a complex in the synaptic vesicle preparation.

How does the phosphorylation of Sept 5 in the synaptic vesicle fraction affect the binding of SNARE proteins to syntaxin-1? Using the HPC-1 syntaxin-1 monoclonal antibody, each fraction was immunoprecipitated and probed with antibodies to SNARE proteins and septin 5 (Fig. 9E). Here, the most significant result is the reduction in the binding of Vamp-2 in the $\mathrm{P} 3$ vesicle fraction (Fig. 9F) $(p<0.05)$. Sept5 binding was minimal; in fact, to 

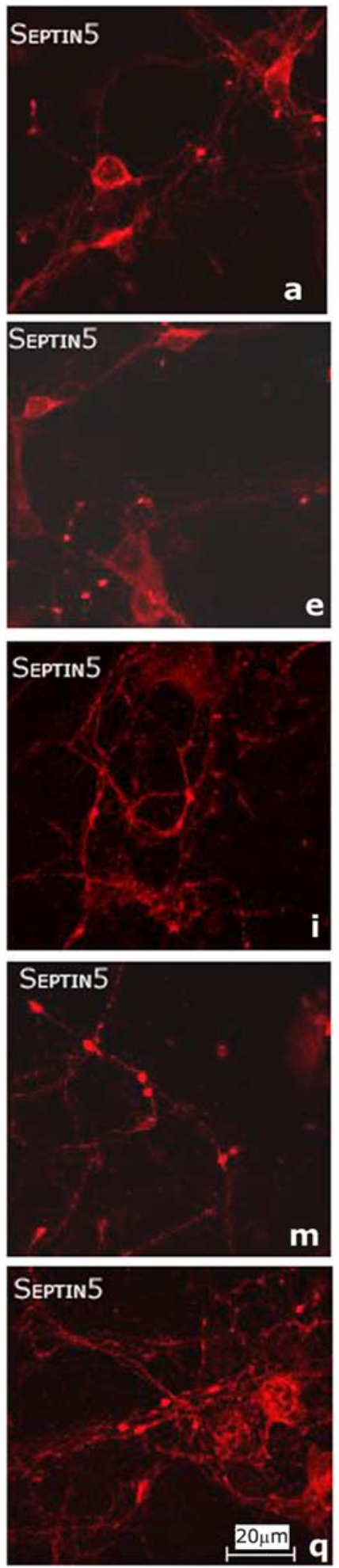
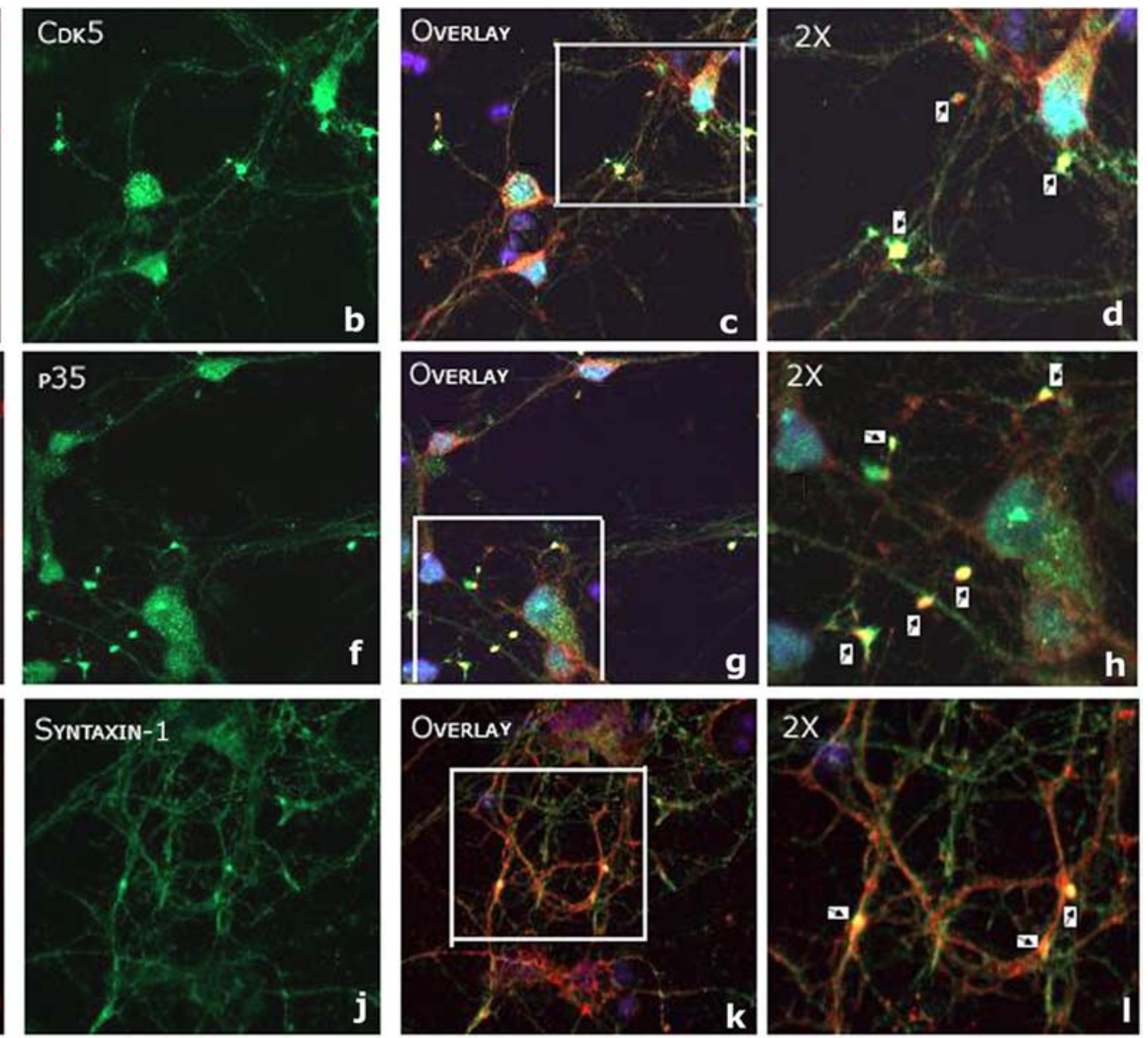

g

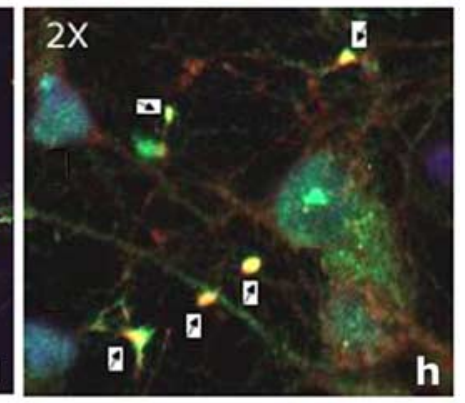

k
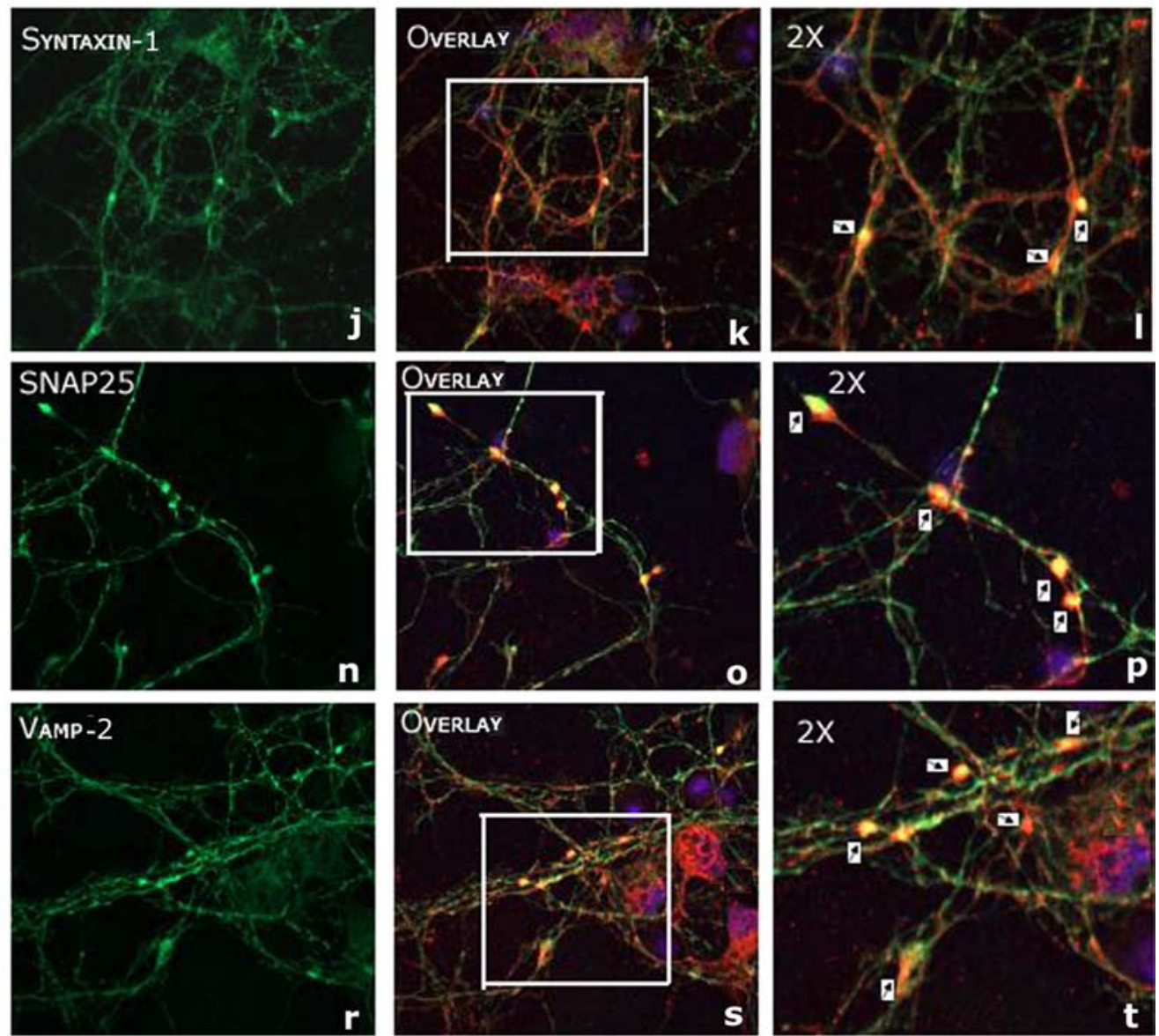

Figure 10. Septin 5 colocalization with SNARE proteins in putative synaptic sites in long-term (2.5 weeks) cultures of rat cortical neurons. $\boldsymbol{a}$ - $\boldsymbol{t}$, E18 rat cortical neurons were immunostained to

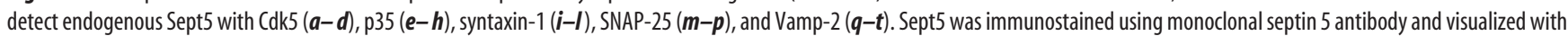
Texas Red $(\boldsymbol{a}, \boldsymbol{e}, \boldsymbol{i}, \boldsymbol{m}, \boldsymbol{q}) ; \boldsymbol{C d k 5}$, p35, syntaxin-1, SNAP-25, and Vamp-2 were immunostained using their respective polyclonal antibodies $(\boldsymbol{b}, \boldsymbol{f}, \boldsymbol{j}, \boldsymbol{n}, \boldsymbol{r})$ and were visualized using Oregon Green. The synaptic colocalizations are shown in yellow in the magnified inserts in the overlays $(\boldsymbol{d}, \boldsymbol{h}, \boldsymbol{I}, \boldsymbol{p}, \boldsymbol{t}$, arrows). Scale bar, $20 \mu \mathrm{m}$.

demonstrate any expression, the blots were overexposed. Note that no Sept5 was seen in the P3 fraction, reflecting its highly phosphorylated state (Fig. $9 C$, lane p3). The increased binding of $\alpha$-SNAP to syntaxin- 1 is also significant ( $p<0.05$ ), suggesting it may replace the relatively low levels of septin 5 binding.
Septin 5 colocalizes with Cdk5/p35 and SNARE proteins in putative synapses in 2.5-week-old rat (E18) cortical neuron cultures

Cortical neuron cultures from E18 rat embryos were cultured for 2.5 weeks to promote synaptic connections among neurites. The 
A
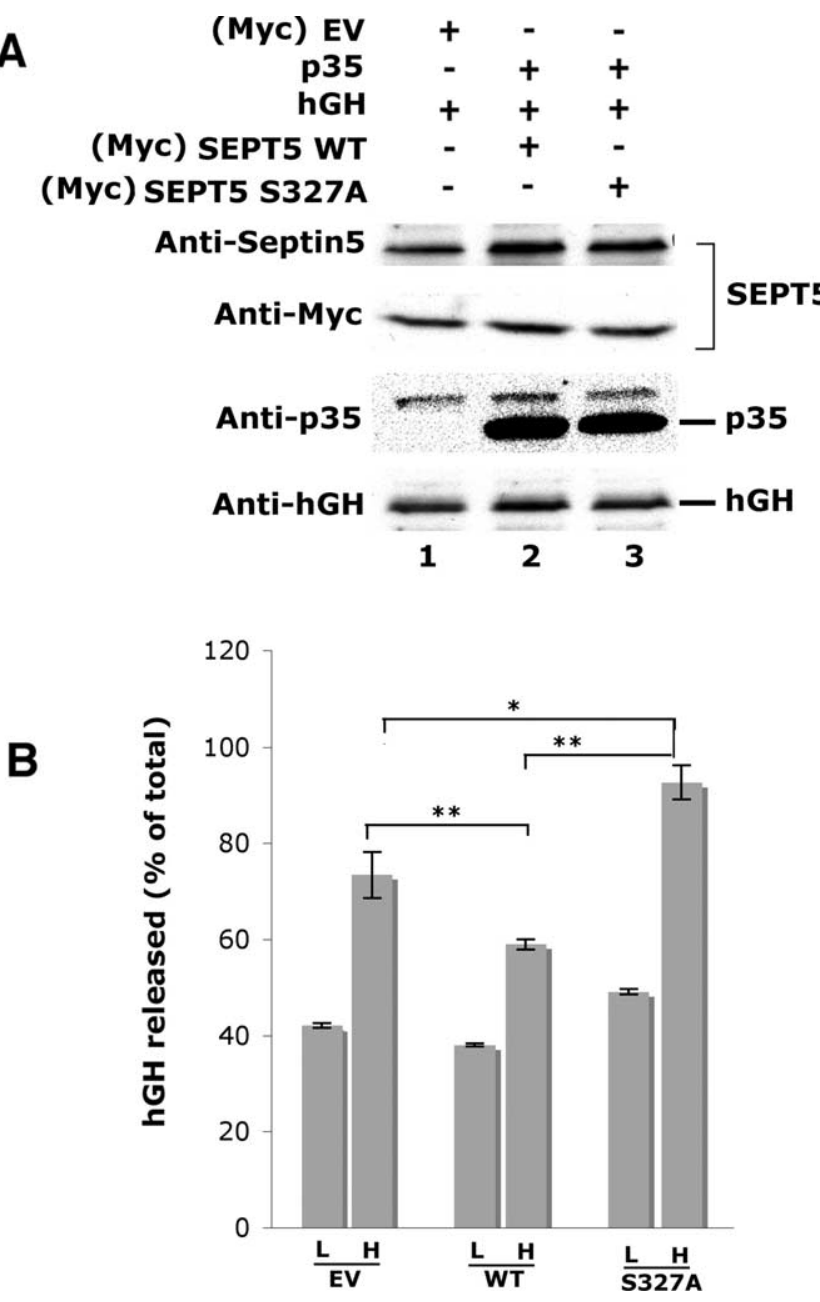

Figure 11. Secretion of human growth hormone in $\mathrm{PC} 12$ cells is enhanced by overexpression of the nonphosphorylated SEPT5 (S327A) mutant. A, Expression constructs encoding hGH were cotransfected into PC12 cells with empty vector (EV), SEPT5 WT, and SEPT5 mutant (S327A) along with $\mathrm{p} 35$. Lysates of transfected $\mathrm{PC} 12$ cells were run on the gel and immunodetected using respective antibodies. The first panel shows the expression of total septin 5 in the lysates, whereas the second panel shows the transfected SEPT5 as immunodetected with Myc antibody. The presence of $\mathrm{p} 35$ was probed with polyclonal p35 antibody and hGH was detected using mouse monoclonal anti hGH antibody. $\boldsymbol{B}$, Culture media with $2.2 \mathrm{mM} \mathrm{Ca}^{2+}$ in the presence of low $(\mathrm{L})$ and high $(\mathrm{H}) \mathrm{K}^{+}$were collected, and the $\mathrm{hGH}$ secreted was assayed by hGH-linked immunosorbent assay. $\mathrm{hGH}$ released is calculated as a percentage of total with EV, with SEPT5 WT, and SEPT5 S327A. Each value shown represents the mean \pm SEM from multiple $(n=9)$ experiments. Statistically significant differences are depicted $\left({ }^{*} p<0.05\right.$; ${ }^{* *} p<0.01$; Student's $t$ test).

cells were prepared for immunocytochemistry and immunostained for septin 5, Cdk5, and several SNARE proteins, including syntaxin-1. The results are shown in Figure 10. In $a-d$, the colocalization of Sept 5 with Cdk5 is seen in putative synaptic sites in the overlap insert in $d$ (arrows). A similar colocalization of Sept 5 with $\mathrm{p} 35$ is seen in $e-h(h$, arrows). The colocalization of Sept 5 to the SNARE proteins, syntaxin-1 $(i-l)$, SNAP-25 $(m-p)$, and Vamp-2 $(q-t)$, is much more evident in putative synapses (note particularly $l, p$, and $t$ ).

\section{Cdk5/p35 phosphorylation of SEPT5 modulates regulated exocytosis in PC12 cells}

Previous studies suggest that septin 5 interacts with syntaxin-1 and is involved in exocytotic secretion (Beites et al., 1999; Taniguchi et al., 2007). Recently, it has been shown that Cdk5 phos- phorylation of a mouse isoform of adult-type septin 5 at S17, near the N-terminal end, does decrease binding to syntaxin-1 (Taniguchi et al., 2007). Here we show that Cdk5 phosphorylation at a S327 site at the C-terminal end of the human isoform of SEPT5 near the coiled-coil region also decreases binding to syntaxin-1. Does phosphorylation at this site affect exocytotic secretion? To determine a possible role of Cdk5 phosphorylation of SEPT5 on secretion, we used PC12 cells, a model system for studying exocytotic secretion (Itakura et al., 1999; Sugita et al., 1999; Khvotchev et al., 2003; Liu et al., 2006). We used a transfection assay in which hGH was coexpressed in PC12 cells with p35 (to promote Cdk5 phosphorylation) together with wild-type or mutant (S327A) SEPT5. Because most transfected cells coexpress both proteins, the secretion of hGH can be used to study the effect of SEPT5 on secretion (Schweitzer and Kelly, 1985). We induced $\mathrm{Ca}^{2+}$-dependent regulated secretion of hGH from PC12 cells with high $\mathrm{K}^{+}$that depolarizes the membrane and triggers exocytosis. First, the transfection efficiency was determined by Western blots of transfected cells (Fig. 11A). The first and second panels show the total septin 5 and the transfected SEPT5, respectively in the transfected cells. The third panel shows the expression of $\mathrm{p} 35$, and the fourth panel shows equal amounts of hGH expressed in all cotransfections. The release of hGH in PC12 cells was measured by a comparison of exposure to low- and high- $\mathrm{K}^{+}$conditions. As shown in Figure $11 \mathrm{~B}$, the results from nine separate experiments in triplicate show that transfection of the SEPT5 mutant (S327A) increased hGH secretion in both low- and high- $\mathrm{K}^{+}$stimulated conditions when compared with SEPT5 wild type. Note that in all cases a significant, almost $50 \%$ increase in secretion was observed at the high $\mathrm{K}^{+}$compared with the low. Furthermore, cells expressing the mutant protein and even the endogenous release from control cells at the high $\mathrm{K}^{+}$concentrations were significantly greater than the secretion from WT cells. These findings suggest that phosphorylation of SEPT5 at S327 modulates exocytotic secretion in PC12 cells.

\section{Discussion}

Using a yeast two-hybrid strategy, we have succeeded in identifying another synaptic protein, SEPT5, as a target of the neuronalspecific kinase Cdk5. Here is another site at which this multifunctional kinase seems to be critically involved in membrane trafficking and exocytosis. Cdk5/p35, localized and enriched in presynaptic terminals in rodent brain, phosphorylates synapsin 1 (Matsubara et al., 1996) and Munc18 (Shuang et al., 1998; Fletcher et al., 1999), regulates synaptic vesicle fusion and release, and plays a role in synaptic vesicle cycling (Tomizawa et al., 2002). Cdk5 phosphorylation is also essential to endocytosis at the nerve terminal, for the tightly regulated recapture of discharged synaptic vesicles into the presynaptic region to maintain the pool of vesicles for synaptic transmission (Nguyen and Bibb, 2003; Tan et al., 2003; Tomizawa et al., 2003). These studies suggest that Cdk5 may be a negative regulator of neurotransmitter release (Cheung et al., 2006). Here we have shown that SEPT5, another protein implicated in exocytosis (Beites et al., 1999, 2005), is a target of Cdk5 phosphorylation in neurons, which affects syntaxin-1 binding and exocytotic secretion. Our results suggest that Cdk5 phosphorylation of human SEPT5 may also act as a negative regulator of exocytosis.

We have shown that SEPT5 binds to and colocalizes with endogenous Cdk5/p35 in cortical neurons, and is phosphorylated in vitro and in vivo by Cdk5/p35 at its S327 residue in the C-terminal domain, adjacent to the coil-coiled region. Metabolic labeling studies with cortical neurons transfected with wild-type and mu- 
tant SEPT5 (S327A) show a significant incorporation of $\left[{ }^{32} \mathrm{P}\right]-$ orthophosphate into wild-type SEPT5 and no incorporation into the mutant. S161, another Cdk5 consensus sequence site in SEPT5, was phosphorylated but much less efficiently. That S327 is the major site of Cdk5 phosphorylation was confirmed by a phospho-specific polyclonal antibody prepared against $\operatorname{Ser}(\mathrm{P})^{327}$, by phosphopeptide mapping of a tryptic digest of Cdk5-phosphorylated SEPT5, and by HPLC and Edman degradation sequencing. Moreover, mass spectrometric phosphoproteomic analyses of mouse fetal and adult brain showed that septin 5 was phosphorylated at S327 and S336, respectively (Ballif et al., 2004; Munton et al., 2007), suggesting that Sept5 is usually in a phosphorylated state in situ.

Cdk5 also phosphorylates a mouse adult septin 5 isoform at S17 in the N-terminal domain, which is absent in human SEPT5 (Taniguchi et al., 2007). Both in vitro and in vivo, only the S17 residue was phosphorylated, although a S336 residue corresponding to the S327 in the human SEPT5 was not phosphorylated. Because the two isoforms of septin 5 are very different in their primary and secondary structures, the availability of specific Cdk5 target sites may differ in each case.

Septin 5 binds syntaxin- 1 and participates in exocytosis (Beites et al., 1999). Its overexpression in HIT-T15 cells inhibits regulated secretion, whereas mutation of S58 to asparagine in the GTPase central core domain evokes more efficient binding to syntaxin and promotes exocytosis. Cdk5 phosphorylation of S17 in the N-terminal domain of the adult-type isoform of septin 5 also reduces syntaxin-1 binding (Taniguchi et al., 2007). We also showed that nonphosphorylated SEPT5 mutant (S327A) bound syntaxin-1 more effectively than the wild type. The nonphosphorylated double mutant (S161A/S327A) exhibited greater syntaxin-1 binding, an additive effect suggesting that tight regulation of septin 5 function at the synapse involves several Cdk5 target sites. A comparison of endogenous syntaxin binding by Sept 5 in Cdk5 KO mouse brains and in Cdk5 knock-down (Cdk5 siRNA-transfected) cortical neurons confirmed that nonphosphorylated Sept5 bound more effectively to syntaxin-1. Significantly, this had no apparent effect on the binding of SNARE proteins to syntaxin- 1 in these crude lysates. In purified synaptic vesicle preparations, however, effects on syntaxin binding to SNARE proteins because of decreased binding to phosphorylated septin 5 were noted. A Cdk5 immunoprecipitate bound Sept5 and phospho-SEPT5 (phosphorylated at S327) in increasing amounts during synaptic vesicle purification while showing a concurrent reduction in the level of syntaxin-1 binding. Does this, in turn, affect syntaxin binding to other SNARE proteins? A syntaxin-1 IP of the same fractions showed only a reduction in the expression of Vamp-2 during the purification. How these changes are related to the function of these proteins in exocytosis is not clear.

Nevertheless, we show here that binding of phosphorylated SEPT5 (WT) to syntaxin-1 significantly reduced regulated secretion from PC12 cells, whereas the transfected nonphosphorylated mutant (S327A), which binds more effectively to syntaxin-1, potentiated secretion in PC12 cells. We also demonstrated colocalization of Sept5, Cdk5/p35, and SNARE proteins in putative synaptic sites in ICC preparations of mature cortical neurons. Together, these data point to septin 5 as an additional target for Cdk5 phosphorylation at the synapse.

The role of septin 5 in exocytosis is not well understood, but it too may depend on phosphorylation/dephosphorylation "switches" that regulate septin filament assembly. Here, we have shown that SEPT5 binding to syntaxin-1 is modulated by Cdk5 phosphorylation at two sites (S161 and S327), which regulates exocytosis. Sept5 has two binding sites for syntaxin-1, the GTPbinding domain in the more central core and the C-terminal coiled-coil region (Beites et al., 2005). It is noteworthy that the S161 site lies within the GTP-binding domain, whereas the S327 site is adjacent to the coiled-coil C-terminal domain. Phosphorylation of these sites can affect syntaxin binding as well as septinseptin filament assembly. Although Sept5 binds directly to syntaxin-1 in the SNARE complex, it is readily displaced by $\alpha$-SNAP, another key protein regulating the SNARE cycle of membrane fusion (Beites et al., 2005). It has been suggested that septin 5 filaments may act as tethers, networks, or meshes that prevent the accessibility of vesicles to the membrane (Beites et al., 2005). Depending on the septin 5 isoform and its specific cellular location, Cdk5 phosphorylation at the $\mathrm{N}$-terminal (S17) domain, the S161 in the GTP-binding domain, or the C-terminal (S327) domain may promote filament formation and decreased binding to syntaxin-1. This may serve as a negative modulator of secretion, perhaps by tethering secretory vesicles during trafficking or as they are recruited at the membrane until signaled to fuse and release their contents. Alternatively, phosphorylation of septins may induce translocation of the septin from membranes to the cytosol as happens with PKG phosphorylation of septin 3. Septin 3 at the nerve terminal membrane is translocated to the cytosol as phospho-septin 3 (Xue et al., 2004). This too may affect binding to SNARE proteins and exocytosis or may even influence the process of endocytotic recycling of spent vesicles.

The SNARE secretion cycle is modulated by phosphorylation at different sites and by different kinases. Phosphorylation of SNAP-25 by PKC or PKA potentiates vesicle recruitment and release (Nagy et al., 2002, 2004). Cdk5 phosphorylation of Munc 18 , a SNARE-associated protein bound to syntaxin, reduces syntaxin binding and also effects the recruitment of vesicles to the membrane (Shuang et al., 1998; Fletcher et al., 1999). The precise mechanisms are not understood, but phosphorylation by $\mathrm{Cdk} 5$ at different sites in specific septin isoforms may reflect a cell-specific mechanism for modulating a common secretory process. Evidently, the role of Cdk5 phosphorylation is defined by the local conditions that govern its interactions with substrates, activators, and sites within the cell. The process must be carefully orchestrated at the membrane by tight regulation of phosphorylation and dephosphorylation with C $\mathrm{dk} 5$ acting as one of the principal switches.

\section{References}

Amin ND, Albers W, Pant HC (2002) Cyclin-dependent kinase 5 (cdk5) activation requires interaction with three domains of p35. J Neurosci Res 67:354-362.

Ballif BA, Villen J, Beausoleil SA, Schwartz D, Gygi SP (2004) Phosphoproteomic analysis of the developing mouse brain. Mol Cell Proteomics 3:1093-1101.

Beites CL, Xie H, Bowser R, Trimble WS (1999) The septin CDCrel-1 binds syntaxin and inhibits exocytosis. Nat Neurosci 2:434-439.

Beites CL, Campbell KA, Trimble WS (2005) The septin Sept5/CDCrel-1 competes with alpha-SNAP for binding to the SNARE complex. Biochem J 385:347-353.

Chae T, Kwon YT, Bronson R, Dikkes P, Li E, Tsai LH (1997) Mice lacking p35, a neuronal specific activator of Cdk5, display cortical lamination defects, seizures, and adult lethality. Neuron 18:29-42.

Chen GC, Yang JT (1997) Two-point calibration of circular dichrometer with d-10-camphorsulfonic acid. Anal Lett 10:1195-1207.

Cheung ZH, Fu AK, Ip NY (2006) Synaptic roles of Cdk5: implications in higher cognitive functions and neurodegenerative diseases. Neuron 50:13-18.

Dhavan R, Tsai LH (2001) A decade of CDK5. Nat Rev Mol Cell Biol 2:749-759. 
Dhavan R, Greer PL, Morabito MA, Orlando LR, Tsai LH (2002) The cyclin-dependent kinase 5 activators p35 and p39 interact with the alphasubunit of $\mathrm{Ca}^{2+} /$ calmodulin-dependent protein kinase II and alphaactinin-1 in a calcium-dependent manner. J Neurosci 22:7879-7891.

Fletcher AI, Shuang R, Giovannucci DR, Zhang L, Bittner MA, Stuenkel EL (1999) Regulation of exocytosis by cyclin-dependent kinase 5 via phosphorylation of Munc18. J Biol Chem 274:4027-4035.

Guszczynski T, Specht SI, Copeland TD (2006) A microtiter plate fraction collector for the sequencing of radioactive phosphorylated peptides. Anal Biochem 356:151-153.

Itakura M, Misawa H, Sekiguchi M, Takahashi S, Takahashi M (1999) Transfection analysis of functional roles of complexin I and II in the exocytosis of two different types of secretory vesicles. Biochem Biophys Res Comm 265:691-696.

Kesavapany S, Lau KF, McLoughlin DM, Brownlees J, Ackerley S, Leigh PN, Shaw CE, Miller CC (2001) p35/cdk5 binds and phosphorylates betacatenin and regulates beta-catenin/presenilin-1 interaction. Eur J Neurosci 13:241-247.

Kesavapany S, Lau KF, Ackerley S, Banner SJ, Shemilt SJ, Cooper JD, Leigh PN, Shaw CE, McLoughlin DM, Miller CC (2003) Identification of a novel, membrane-associated neuronal kinase, cyclin-dependent kinase 5/p35-regulated kinase. J Neurosci 23:4975-4983.

Kesavapany S, Amin N, Zheng YL, Nijhara R, Jaffe H, Sihag R, Gutkind JS, Takahashi S, Kulkarni A, Grant P, Pant HC (2004) p35/cyclindependent kinase 5 phosphorylation of ras guanine nucleotide releasing factor 2 (RasGRF2) mediates Rac-dependent extracellular signalregulated kinase $1 / 2$ activity, altering RasGRF2 and microtubuleassociated protein $1 \mathrm{~b}$ distribution in neurons. J Neurosci 24:4421-4431.

Khvotchev MV, Ren M, Takamori S, Jahn R, Sudhof TC (2003) Divergent functions of neuronal Rab1 $1 \mathrm{~b}$ in $\mathrm{Ca}^{2+}$-regulated versus constitutive exocytosis. J Neurosci 23:10531-10539.

Lai KO, Ip NY (2003) Central synapse and neuromuscular junction: same players, different roles. Trends Genet 19:395-402.

Lew J, Beaudette K, Litwin CM, Wang JH (1992a) Purification and characterization of a novel proline-directed protein kinase from bovine brain. J Biol Chem 267:13383-13390.

Lew J, Winkfein RJ, Paudel HK, Wang JH (1992b) Brain proline-directed protein kinase is a neurofilament kinase which displays high sequence homology to p34cdc2. J Biol Chem 267:25922-25926.

Li BS, Zhang L, Gu J, Amin ND, Pant HC (2000) Integrin alpha(1) beta(1)mediated activation of cyclin-dependent kinase 5 activity is involved in neurite outgrowth and human neurofilament protein $\mathrm{H}$ Lys-Ser-Pro tail domain phosphorylation. J Neurosci 20:6055-6062.

Liu Y, Cheng K, Gong K, Fu AK, Ip NY (2006) Pctairel phosphorylates $\mathrm{N}$-ethylmaleimide-sensitive fusion protein: implications in the regulation of its hexamerization and exocytosis. J Biol Chem 281:9852-9858.

Macara IG, Baldarelli R, Field CM, Glotzer M, Hayashi Y, Hsu SC, Kennedy MB, Kinoshita M, Longtine M, Low C, Maltais LJ, McKenzie L, Mitchison TJ, Nishikawa T, Noda M, Petty EM, Peifer M, Pringle JR, Robinson PJ, Roth D, et al. (2002) Mammalian septins nomenclature. Mol Biol Cell 13:4111-4113.

Matsubara M, Kusubata M, Ishiguro K, Uchida T, Titani K, Taniguchi H (1996) Site-specific phosphorylation of synapsin I by mitogen-activated protein kinase and Cdk5 and its effects on physiological functions. J Biol Chem 271:21108-21113.

McPhie P (2001) Circular dichroism studies on proteins in films and in solution: estimation of secondary structure by g-factor analysis. Anal Biochem 293:109-119.

Munton RP, Tweedie-Cullen R, Livingstone-Zatchej M, Weinandy F, Waidelich M, Longo D, Gehrig P, Potthast F, Rutishauser D, Gerrits B, Panse C, Schlapbach R, Mansuy IM (2007) Qualitative and quantitative analyses of protein phosphorylation in naive and stimulated mouse synaptosomal preparations. Mol Cell Proteomics 6:283-293.

Nagy G, Matti U, Nehring RB, Binz T, Rettig J, Neher E, Sorensen JB (2002) Protein kinase C-dependent phosphorylation of synaptosome-associated protein of $25 \mathrm{kDa}$ at Ser 187 potentiates vesicle recruitment. J Neurosci 22:9278-9286.
Nagy G, Reim K, Matti U, Brose N, Binz T, Rettig J, Neher E, Sorensen JB (2004) Regulation of releasable vesicle pool sizes by protein kinase A-dependent phosphorylation of SNAP-25. [see comment] Neuron 41:417-429.

Nguyen C, Bibb JA (2003) Cdk5 and the mystery of synaptic vesicle endocytosis. J Cell Biol 163:697-699.

Nikolic M, Dudek H, Kwon YT, Ramos YF, Tsai LH (1996) The cdk5/p35 kinase is essential for neurite outgrowth during neuronal differentiation. Genes Dev 10:816-825.

Ohshima T, Ward JM, Huh CG, Longenecker G, Veeranna, Pant HC, Brady RO, Martin LJ, Kulkarni AB (1996) Targeted disruption of the cyclindependent kinase 5 gene results in abnormal corticogenesis, neuronal pathology and perinatal death. Proc Natl Acad Sci USA 93:11173-11178.

Paglini G, Peris L, Diez-Guerra J, Quiroga S, Caceres A (2001) The Cdk5p35 kinase associates with the Golgi apparatus and regulates membrane traffic. EMBO Rep 2:1139-1144.

Roz N, Mazur Y, Hirshfeld A, Rehavi M (2002) Inhibition of vesicular uptake of monoamines by hyperforin. Life Sci 71:2227-2237.

Schweitzer ES, Kelly RB (1985) Selective packaging of human growth hormone into synaptic vesicles in a rat neuronal (PC12) cell line. J Cell Biol 101:667-676.

Shuang R, Zhang L, Fletcher A, Groblewski GE, Pevsner J, Stuenkel EL (1998) Regulation of Munc-18/syntaxin 1A interaction by cyclindependent kinase 5 in nerve endings. J Biol Chem 273:4957-4966.

Sihag RK, Jaffe H, Nixon RA, Rong X (1999) Serine-23 is a major protein kinase A phosphorylation site on the amino-terminal head domain of the middle molecular mass subunit of neurofilament proteins. J Neurochem 72:491-499.

Smillie KJ, Cousin MA (2005) Dynamin I phosphorylation and the control of synaptic vesicle endocytosis. Biochem Soc Symp 87-97.

Sugita S, R J, TC S (1999) Synaptogyrins regulate Ca2+-dependent exocytosis in PC12 cells. J Biol Chem 274:18893-18901.

Tan TC, Valova VA, Malladi CS, Graham ME, Berven LA, Jupp OJ, Hansra G, McClure SJ, Sarcevic B, Boadle RA, Larsen MR, Cousin MA, Robinson PJ (2003) Cdk5 is essential for synaptic vesicle endocytosis. Nat Cell Biol 5:701-710.

Taniguchi M, Taoka M, Itakura M, Asada A, Saito T, Kinoshita M, Takahashi M, Isobe T, Hisanaga S (2007) Phosphorylation of adult type Sept5 (CDCrel-1) by cyclin-dependent kinase 5 inhibits interaction with syntaxin-1. J Biol Chem 282:7869-7876.

Tomizawa K, Ohta J, Matsushita M, Moriwaki A, Li ST, Takei K, Matsui H (2002) Cdk5/p35 regulates neurotransmitter release through phosphorylation and downregulation of P/Q-type voltage-dependent calcium channel activity. J Neurosci 22:2590-2597.

Tomizawa K, Sunada S, Lu YF, Oda Y, Kinuta M, Ohshima T, Saito T, Wei FY, Matsushita M, Li ST, Tsutsui K, Hisanaga S, Mikoshiba K, Takei K, Matsui H (2003) Cophosphorylation of amphiphysin I and dynamin I by Cdk5 regulates clathrin-mediated endocytosis of synaptic vesicles. J Cell Biol 163:813-824.

Tsai LH, Delalle I, Caviness Jr VS, Chae T, Harlow E (1994) p35 is a neuralspecific regulatory subunit of cyclin-dependent kinase 5 . Nature 371:419-423

Veeranna, Amin ND, Ahn NG, Jaffe H, Winters CA, Grant P, Pant HC (1998) Mitogen-activated protein kinases (Erk1,2) phosphorylate LysSer-Pro (KSP) repeats in neurofilament proteins NF-H and NF-M. J Neurosci 18:4008-4021.

Wang X, Ching YP, Lam WH, Qi Z, Zhang M, Wang JH (2000) Identification of a common protein association region in the neuronal Cdk5 activator. J Biol Chem 275:31763-31769.

Xue J, Tsang CW, Gai WP, Malladi CS, Trimble WS, Rostas JA, Robinson PJ (2004) Septin 3 (G-septin) is a developmentally regulated phosphoprotein enriched in presynaptic nerve terminals. J Neurochem 91:579-590.

Zheng YL, Li BS, Kanungo J, Kesavapany S, Amin N, Grant P, Pant HC (2007) Cdk5 Modulation of mitogen-activated protein kinase signaling regulates neuronal survival. Mol Biol Cell 18:404-413. 